\title{
Understanding predicted shifts in diazotroph biogeography using resource competition theory
}

\author{
S. Dutkiewicz ${ }^{1}$, B. A. Ward ${ }^{2}$, J. R. Scott ${ }^{1}$, and M. J. Follows ${ }^{3}$ \\ ${ }^{1}$ Center for Global Change Science and Department of Earth, Atmospheric and Planetary Sciences, Massachusetts Institute of \\ Technology, Cambridge, MA 02139, USA \\ ${ }^{2}$ Laboratoire des Sciences de l'Environnement Marin, Institut Universitaire Européen de la Mer, Plouzané, France \\ ${ }^{3}$ Department of Earth, Atmospheric and Planetary Sciences, Massachusetts Institute of Technology, Cambridge, MA 02139, \\ USA
}

Correspondence to: S. Dutkiewicz (stephd@mit.edu)

Received: 8 April 2014 - Published in Biogeosciences Discuss.: 19 May 2014

Revised: 26 August 2014 - Accepted: 5 September 2014 - Published: 8 October 2014

\begin{abstract}
We examine the sensitivity of the biogeography of nitrogen fixers to a warming climate and increased aeolian iron deposition in the context of a global earth system model. We employ concepts from the resource-ratio theory to provide a simplifying and transparent interpretation of the results. First we demonstrate that a set of clearly defined, easily diagnosed provinces are consistent with the theory. Using this framework we show that the regions most vulnerable to province shifts and changes in diazotroph biogeography are the equatorial and South Pacific, and central Atlantic. Warmer and dustier climates favor diazotrophs due to an increase in the ratio of supply rate of iron to fixed nitrogen. We suggest that the emergent provinces could be a standard diagnostic for global change models, allowing for rapid and transparent interpretation and comparison of model predictions and the underlying mechanisms. The analysis suggests that monitoring of real world province boundaries, indicated by transitions in surface nutrient concentrations, would provide a clear and easily interpreted indicator of ongoing global change.
\end{abstract}

\section{Introduction}

Nitrogen fixation is a major source of exogenous nitrogen to the global ocean and thus plays a critical role in the nitrogen cycle and consequently for marine ecosystems. Potential alterations in the distribution of nitrogen fixing autotrophs (diazotrophs) as the climate changes will therefore have important ramifications.

The observed biogeography of diazotrophs can be understood as a function of nutrient supply ratios (Dutkiewicz et al., 2012, Ward et al., 2013) using concepts from Tilman (1982), with the growth of diazotrophs dependent on an excess supply of both iron and phosphorus over nitrogen, relative to the demands of the non-diazotroph community. The slower growth rates and increased iron requirements associated with nitrogen fixation (Berman-Frank et al., 2001; Kustka et al., 2003) mean that diazotrophs will be outcompeted if dissolved inorganic phosphorus $(\mathrm{P})$ or iron $(\mathrm{Fe}) \mathrm{lim}$ its them and their non-diazotroph competitors.

The global ocean can be described by six biogeochemical provinces based on resource supply ratios (see Ward et al., 2013; briefly summarized in Sect. 3) with diazotrophs only present in the two provinces where both the $\mathrm{Fe}: \mathrm{N}$ and $\mathrm{P}: \mathrm{N}$ supply ratios exceed given criteria. The theory also suggests that the limiting nutrients in the euphotic layer are held at eco-physiologically determined low values, while nonlimiting nutrients accumulate according to the excess supply. Ward et al. (2013) showed that these theoretical predictions are consistent with observations along the Atlantic Meridional Transect (Moore et al., 2009), nutrient data from the World Ocean Atlas (Garcia et al., 2006) and in observed diazotroph distribution (Luo et al., 2012). This framework has also been used to understand the observed shifts in nutrient gradients (interpreted as province boundaries) that occur due 
to seasonal changes in iron deposition in the equatorial Atlantic (Schlosser et al., 2013).

Nutrient supplies will change in a warming climate. Model studies have suggested a reduction of macronutrient supply to the surface ocean in a warming ocean (Bopp et al., 2001; Steinacher et al., 2010; Dutkiewicz et al., 2013). Likewise, the aeolian iron supply, a major source of bioavailable iron to the ocean, has changed markedly in the past and is likely to change in the future (Mahowald and Luo, 2003; Mahowald et al., 2006; Tegen et al., 2004). Model studies have suggested that such changes will impact phytoplankton. Reduction in macronutrients to the surface is likely to reduce primary production in some regions of a warmer world (e.g. Bopp et al., 2001; Dutkiewicz et al., 2013) and changes in iron supply have been shown to impact nitrogen fixation rates (e.g. Krishnamurthy et al., 2009; Tagliabue et al., 2008). Here we show how the resource supply ratio provides a framework to interpret model predictions.

We focus on how the relative change in nutrient supply will affect the biogeography of diazotrophs and the implication for global nitrogen fixation. We apply the province based theory (Dutkiewicz et al., 2012, Ward et al., 2013) to understand the ecological changes that occur as an earth system model is subject to changes in global temperature and atmospheric dust deposition. We first introduce the numerical model (Sect. 2) and results from two hypothetical scenarios of a changing ocean. We use the theoretical framework to map out the provinces and nutrient controls (Sect. 3), and in particular to explain the systems response in climate changes scenarios (Sect. 4). We discuss implications and limitations of out study in Sect. 5.

\section{Global numerical model}

We use the MIT Integrated Global Systems Model (IGSM) (Dutkiewicz et al., 2005, 2013; Scott et al., 2008; Sokolov et al., 2009), an earth system model of intermediate complexity together with a biogeochemistry and ecosystem model (Dutkiewicz et al., 2009, 2012), as our laboratory for this study. The model resolves the cycling of carbon, phosphorus, nitrogen, silica, iron and oxygen through inorganic, living, dissolved and particulate organic phases. We resolve several non-diazotroph autotrophs, two diazotrophs and two grazers. See Appendix A for more details and changes relative to our previous studies.

In a control simulation with pre-industrial climate and dust supply (Luo et al., 2008), we find plausible ecological and biogeochemical distributions (similar to Dutkiewicz et al., 2013). In particular the relevant nutrient distributions compare well to observations (Fig. 1a-d). The model underestimates nitrate in the high Northern Hemisphere, but has reasonable values in the sub-tropics and equatorial regions. Iron has lowest concentrations in the equatorial Pacific as is observed (though note the paucity of observations), and we appear to overestimate the iron limitation in the South Pacific gyres. Otherwise we capture the high iron concentration in the Atlantic and the northern Indian oceans, with lower values elsewhere. We find a distribution of diazotrophs (Fig. 1e and f) which is consistent with the observed distribution of diazotrophs (Luo et al., 2012), though again, note the limitation of the observations. We capture high diazotroph biomass in the tropical Atlantic, though our maximum is slightly south relative to the observations. In particular, we also capture the observed lack of diazotrophs in regions such as the South Pacific gyres and Pacific equatorial region (see Monteiro et al., 2010; Luo et al., 2012) and consistent with the lack of isotopic evidence for nitrogen fixation in the middle of the North Atlantic gyre (Knapp et al., 2005, 2008). The numerical model is less consistent with rates of nitrogen fixation found by Luo et al. (2012, and further described in Luo et al., 2014) especially in the South Pacific (where our model suggests less nitrogen fixation) and South Atlantic (where the model suggests higher). The Luo et al. (2012) compilation does not differentiate between heterotrophic and autotrophic nitrogen fixation, while our model focuses only on autotrophic diazotrophy. Nitrogen fixation in the South Pacific is likely dominated by heterotrophs (Halm et al., 2012). Using hydrogen supersaturation, Moore et al. (2014) suggests higher nitrogen fixation in the South Atlantic than previous observations had found.

To explore how the diazotroph distribution shifts in altered climates, we conducted a series of sensitivity experiments (Table 1, and see Appendix A). Here we discuss two key simulations which reveal the contributions of changes in ocean circulation and changes in iron deposition independently:

- Phys: from pre-industrial conditions, the system is perturbed with changes to the physical ocean (e.g. temperature, circulation and mixing) as a result of increasing greenhouse gases in a "business-as-usual" emission scenario (Sokolov et al., 2009; Dutkiewicz et al., 2013; similar to RCP8.5). Dust-borne iron supplies are, however, maintained at pre-industrial values (Luo et al., 2008). There is a significant increase in the geographical extent of the diazotrophs particularly in the equatorial and South Pacific by the end of the projected 21st century (Fig. 2b). The area of ocean sustaining diazotrophs increases by $17 \%$ and the total global nitrogen fixation rate also increases by $17 \%$ (Table 2 ).

- Hilron: to explore the response to changes in iron supply, this experiment has iron dust fluxes that are doubled relative to the pre-industrial values, but the physical ocean is held at pre-industrial conditions. In this experiment there is also an increase in the biogeographical distribution of diazotrophs in similar regions to Phys (Fig. 2c), with $38 \%$ more area and a $28 \%$ increase in global nitrogen fixation. 

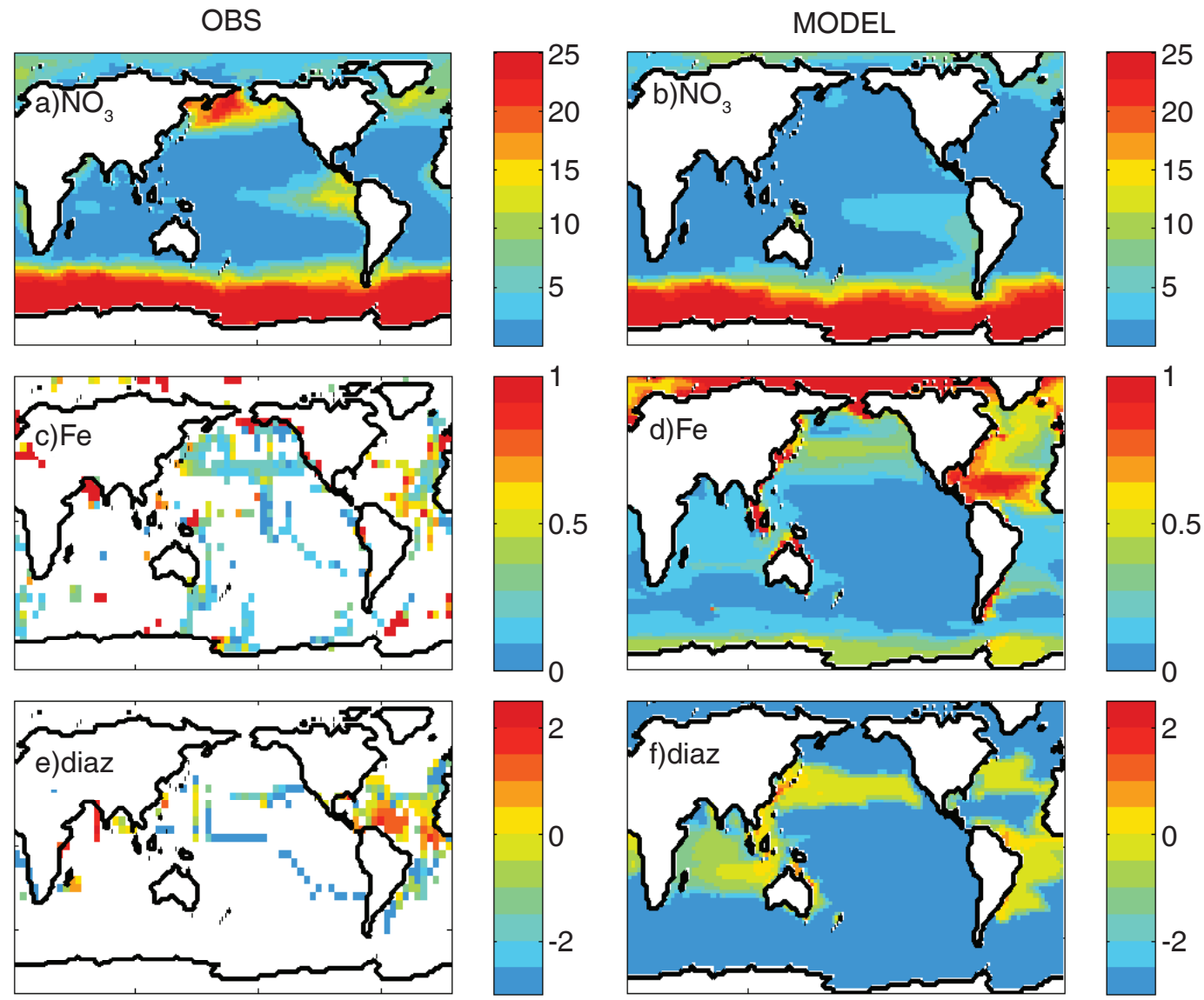

Figure 1. Observations and model over top $50 \mathrm{~m}$ : (a) World Ocean Atlas (Garcia et al., 2006) annual mean nitrate $\left(\mathrm{mmol} \mathrm{m}^{-3}\right)$; (b) model pre-industrial annual mean nitrate $\left(\mathrm{mmol} \mathrm{m}^{-3}\right)$; (c) composite of all iron measurement in top $50 \mathrm{~m}\left(\mathrm{nmol} \mathrm{m}^{-3}\right)$ from compilation of Tagliabue et al. (2012); (d) model pre-industrial annual mean iron $\left(\mathrm{mmol} \mathrm{m}^{-3}\right)$; (e) composite of all diazotroph biomass measurement $\left(\log \mathrm{mg} \mathrm{C}^{-3}\right.$ ) from compilation of Luo et al. (2012); (f) model pre-industrial annual mean diazotroph biomass $\left(\log \mathrm{mg} \mathrm{C}^{-3}\right)$. Note that composites in (c) and (e) are made with all available data without regard to date, so do not represent annual mean.

Why do both experiments show similar shifts in diazotrophs biogeography given such different alterations to the environment? These results, and the dynamics of the system are most easily interpreted using the province structures associated with resource supply ratios.

\section{Understanding global model results with theory}

Before considering the changing distributions of the sensitivity studies (HiIron, Phys), we consider the diazotroph biogeography of the Control (pre-industrial) simulation. We find resource-ratio theory to be key for understanding the significantly more complex global numerical model.

Our theoretical framework (Tables 3 and 4) is based on resource competition (Tilman, 1982) and builds directly on our earlier studies Dutkiewicz et al. (2012) and Ward et al. (2013). We consider two groups of phytoplankton (Eqs. 1 and 2, Table 4): non-diazotrophs (P) whose growth can be limited by nitrate, phosphate or iron; and diazotrophs
(D) who fix all the nitrogen that they require (relaxing this assumption makes no qualitative difference to our results, Dutkiewicz et al., 2012). We assume here a simple linear loss rate for both phytoplankton. The time rate of change of nutrients $(i=\mathrm{N}, \mathrm{P}, \mathrm{Fe}$, Eqs. 3-5, Table 4) are a combination of phytoplankton uptake, sources $I_{i}$ (e.g. transport into a location, dust supplies, remineralization of organic matter) and sinks $O_{i}$ (e.g. transport out of a location, and in the case of iron, scavenging). We make a key assumption (supported by data, e.g. Berman-Frank et al., 2001; Kustka et al., 2003) that diazotrophs have a slower maximum growth rate than the non-diazotrophs.

When growth and losses are tightly coupled, equilibrium solutions are relevant, as is the case subtropical, oligotrophic regions (Dutkiewicz et al., 2009). In the theoretical framework, we solve for equilibrium concentration of phytoplankton and nutrients (Eqs. 6-10, Table 4). For the purpose of this study, we explore the important conclusions of the theoretical framework with the numerical model results, and we 
a) Control
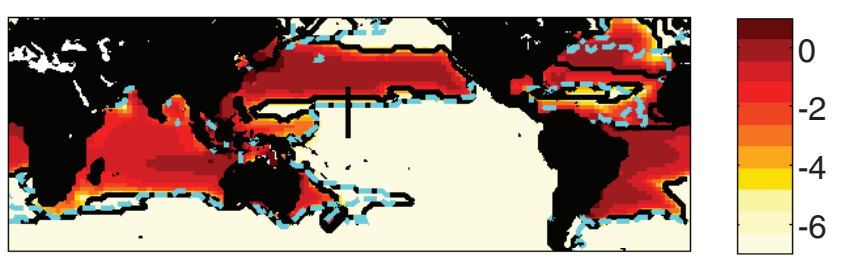

b) Phys (2100)
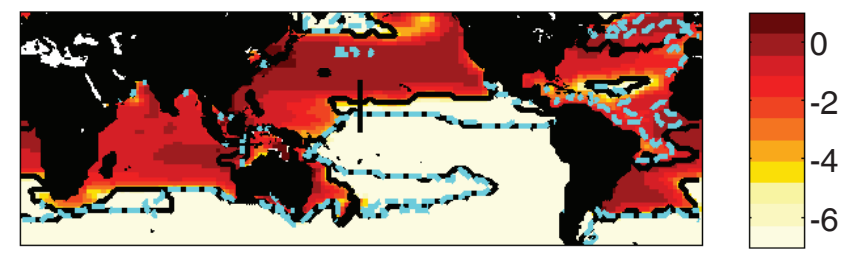

c) Hilron
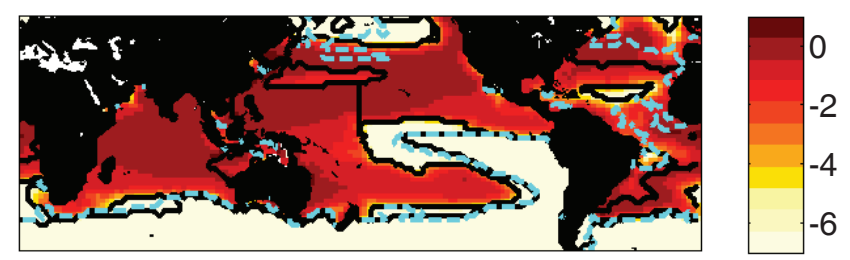

Figure 2. Nitrogen fixation rates $\left(\log \mathrm{g} \mathrm{N} \mathrm{m}^{-2} \mathrm{yr}^{-1}\right.$, annual average) for (a) pre-industrial conditions (experiment Control); (b) 2100 conditions if physical fields, including ocean temperature change in a business as usual emission scenario but with pre-industrial iron dust supply (experiment Phys); (c) conditions if physical fields remain as if for pre-industrial, but iron dust supply is doubled (experiment HiIron). Dashed blue line bounds regions where both $\phi_{\mathrm{PN}}>1$ and $\phi_{\mathrm{FeN}}>1$ (discussed in Section 3.3). Black contours indicate the province boundaries in Fig. 3. Black line in Pacific indicates the transect show in Figs. 4 and 8.

direct the reader to Ward et al. (2013) and Appendix B for further details.

\subsection{Provinces, co-existence, nutrient limitation}

Theory: because of their lower growth rate, diazotrophs can only co-exist with non-diazotrophs if the non-diazotrophs are nitrogen limited. We define six distinct provinces, related to whether diazotrophs coexist with non-diazotrophs and by whether growth of the different phytoplankton are limited by iron, phosphate or, in the case of non-diazotrophs, by DIN (Table 5).

Numerical Model: non-diazotrophs are DIN limited in light blue, green, yellow and dark blue regions (provinces II, III, IV, V, Fig. 3). Diazotrophs and non-diazotrophs coexist in the green and yellow provinces (III and IV), and are limited by iron and phosphate, respectively. a) Control

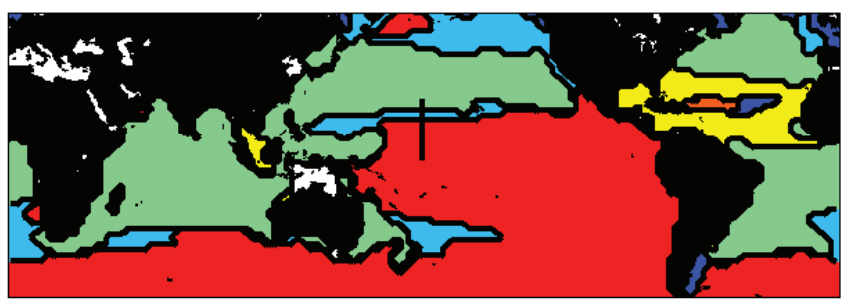

b) Phys (2100)

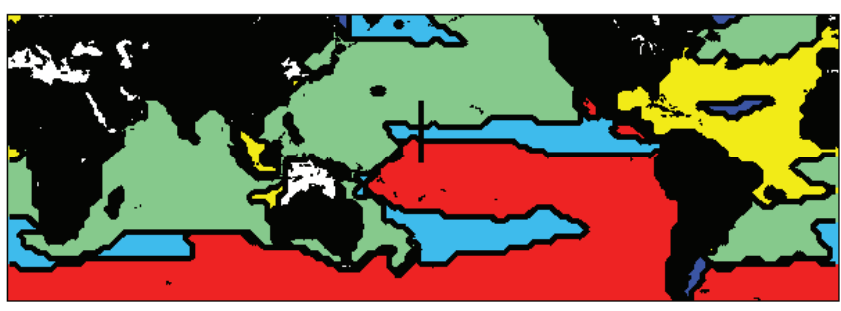

c) Hilron
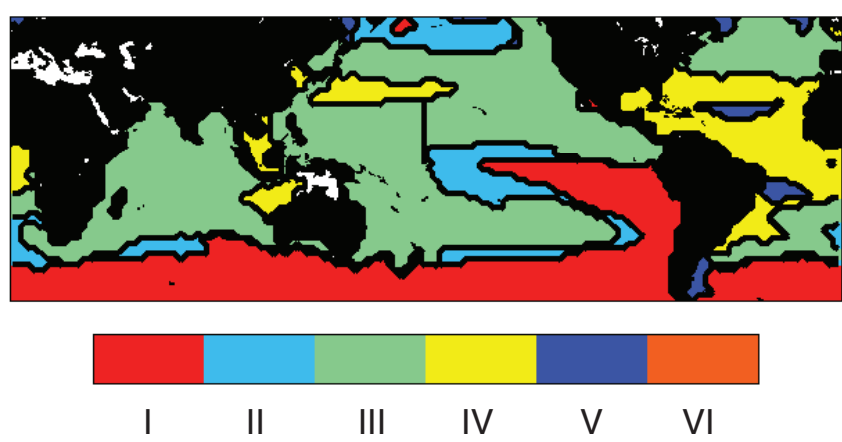

Figure 3. Subtropical/tropical provinces in the numerical model, defined only by whether diazotrophs and non-diazotrophs co-exist and by which nutrient limits the phytoplankton (first three lines of Table 5) for (a) pre-industrial conditions (experiment Control); (b) Phys at 2100; (c) HiIron. Note unshaded regions (except for Mediterranean which is not resolved in this setup) did not fit into the six province categories. Black line in Pacific indicates the transect shown in Figs. 4 and 8.

In province I (red in Fig. 3), where there is very little iron supply, non-diazotrophs are iron limited (line 3 of Table 5) and diazotrophs are excluded (line 1 of Table 5). In regions with more iron supply, non-diazotrophs will be nitrogen limited but there may still not be enough iron to support diazotrophs (province II, light blue in Fig. 3). In a region with enough excess iron, diazotrophs can co-exist: they will be iron limited (line 2 of Table 5) while non-diazotrophs are still nitrogen limited (province III, yellow). With even higher iron supply, diazotrophs are relieved of iron limitation and are instead phosphate limited (province IV, green). However if phosphate supply is not enough to provide excess, diazotrophs will be excluded (province V, dark blue). Even lower phosphate supply will lead to non-diazotrophs being phosphate limited (province VI, orange). Note that these last 
Table 1. Sensitivity experiments.

\begin{tabular}{|c|c|c|c|}
\hline & $\begin{array}{l}\text { Temperature for } \\
\text { growth rate }\end{array}$ & $\begin{array}{l}\text { Circulation/ } \\
\text { mixing }\end{array}$ & Iron dust \\
\hline Control & pre-industrial & pre-industrial & pre-industrial \\
\hline Phys & $1860-2100$ & $1860-2100$ & pre-industrial \\
\hline HiIron & pre-industrial & pre-industrial & double \\
\hline Phys-Temp & $1860-2100$ & pre-industrial & pre-industrial \\
\hline Phys-Circ & pre-industrial & $1860-2100$ & pre-industrial \\
\hline Phys + HiIron & $1860-2100$ & $1860-2100$ & double \\
\hline LoIron & pre-industrial & pre-industrial & half \\
\hline Phys + LoIron & $1860-2100$ & $1860-2100$ & half \\
\hline
\end{tabular}

Table 2. Differences between global integrated results of sensitivity experiments to Control.

\begin{tabular}{llll}
\hline & $\begin{array}{l}\text { Diaz } \\
\text { area }\end{array}$ & $\begin{array}{l}\mathrm{N}_{2} \\
\text { fixation }\end{array}$ & $\begin{array}{l}\text { Primary } \\
\text { production }\end{array}$ \\
\hline Phys & $+17 \%$ & $+17 \%$ & $-3 \%$ \\
HiIron & $+38 \%$ & $+28 \%$ & $+3 \%$ \\
Phys-Temp & $+6 \%$ & $+19 \%$ & $+8 \%$ \\
Phys-Circ & $+14 \%$ & $0 \%$ & $-11 \%$ \\
Phys+HiIron & $+62 \%$ & $+28 \%$ & $-2 \%$ \\
LoIron & $-27 \%$ & $-9 \%$ & $-4 \%$ \\
Phys+LoIron & $-2 \%$ & $+4 \%$ & $-7 \%$ \\
\hline
\end{tabular}

two provinces only occur in small regions of the Atlantic in this model.

\subsection{Ecological control of nutrients}

Theory: resource competition theory suggests that the limiting nutrient is controlled ecologically: in equilibrium (denoted by superscript ${ }^{*}$ ) the phytoplankton draw the nutrient that limits them down to a specific value that is set by the plankton physiology and mortality (see Table 4, Eqs. 6-10). Where non-diazotrophs (B) are nitrogen limited (provinces II-V), inorganic nitrogen is drawn down to $\mathrm{N}_{\mathrm{B}}^{*}$. In province I where non-diazotrophs are iron limited, iron is drawn down to $\mathrm{Fe}_{\mathrm{B}}^{*}$, and in province III iron-limited diazotrophs (D) draw iron down to $\mathrm{Fe}_{\mathrm{D}}^{*}$. Similarly, phosphate is drawn down to $\mathrm{P}_{\mathrm{B}}^{*}$ in province IV and $\mathrm{P}_{\mathrm{D}}^{*}$ in province VI.

Numerical Model: in the model nutrients are drawn down low in provinces where they are ecologically controlled and and are higher in provinces where they are not. For instance in a transect in the Pacific (Fig. 4c-e), iron is drawn down lowest in province $\mathrm{I}$ (to $\mathrm{Fe}_{\mathrm{B}}^{*}$ ) with a increase in concentration into province II and III. In province III iron will be maintained at $\mathrm{Fe}_{\mathrm{D}}^{*}$ which is greater than $\mathrm{Fe}_{\mathrm{B}}^{*}$. In the numerical model $\mathrm{Fe}_{\mathrm{B}}^{*}$ and $\mathrm{Fe}_{\mathrm{D}}^{*}$ are not uniform values, but are a function of the dominant phytoplankton types (affecting $\mu_{j}, \kappa_{i j}$ and $m_{j}$ ), temperature and light environment (as these impact $\mu_{j}$ ), and grazing pressure. Thus even within province I and III, there are variations in the iron concentrations. DIN
Table 3. Theoretical framework variable and parameter description.

\begin{tabular}{ll}
\hline $\mathrm{B}$ & non-diazotroph biomass \\
$\mathrm{D}$ & diazotroph biomass \\
$\mathrm{N}$ & dissolved inorganic nitrogen (DIN) \\
$\mathrm{P}$ & phosphate \\
$\mathrm{Fe}$ & dissolved inorganic iron \\
$I_{i}$ & supply rate of nutrient $i=\mathrm{N}, \mathrm{P}, \mathrm{Fe}$ \\
$O_{i}$ & sink rate of nutrient $i=\mathrm{N}, \mathrm{P}, \mathrm{Fe}$ \\
$\mu_{j}$ & maximum growth rate of plankton $j=\mathrm{B}, \mathrm{D}$ \\
$m_{j}$ & loss rate of plankton $j=\mathrm{B}, \mathrm{D}$ \\
$\kappa_{i j}$ & half saturation constant of nutrient $i=\mathrm{N}, \mathrm{P}, \mathrm{Fe}$ \\
& for plankton $j=\mathrm{B}, \mathrm{D}$ \\
$R_{\mathrm{N} i j}$ & elemental ratio of $\mathrm{N}$ to $i=\mathrm{P}, \mathrm{Fe}$ \\
& in plankton $j=\mathrm{B}, \mathrm{D}$ \\
\hline$\phi_{\mathrm{PN}}$ & $\frac{I_{\mathrm{P}}^{*}}{R_{\mathrm{NP}} I_{\mathrm{N}}^{*}}$ \\
$\phi_{\mathrm{FeN}}$ & $\frac{I_{\mathrm{Fe}}^{*}}{R_{\mathrm{NFe}} I_{\mathrm{N}}^{*}}$ \\
\hline &
\end{tabular}

is drawn down in province III (where non-diazotrophs control it), while phosphate remains high and not ecologically controlled for all three provinces depicted here. Similar patterns occur for a transect between provinces IV, V and VI (not shown), but instead phosphate and DIN are respectively ecologically controlled and iron remains high.

\subsection{Nutrient supply ratio controls provinces boundaries}

Theory: the boundaries between provinces are controlled by the rates at which iron and phosphate are delivered relative to DIN, normalized by the elemental stoichiometry of the nondiazotrophs $\left(R_{\mathrm{NP}_{\mathrm{B}}}, R_{\mathrm{NFe}_{\mathrm{B}}}\right)$ :

$$
\begin{aligned}
\phi_{\mathrm{PN}} & =\frac{I_{\mathrm{P}}^{*}}{R_{\mathrm{NP}_{\mathrm{B}}} I_{\mathrm{N}}^{*}} \\
\phi_{\mathrm{FeN}} & =\frac{I_{\mathrm{Fe}}^{*}}{R_{\mathrm{NFe}_{\mathrm{B}}} I_{\mathrm{N}}^{*}} .
\end{aligned}
$$

Both $\phi_{\mathrm{PN}}$ and $\phi_{\mathrm{FeN}}$ need to be great enough for excess $\mathrm{P}$ and $\mathrm{Fe}$ to accumulate to reach $\mathrm{P}_{\mathrm{D}}^{*}$ and $\mathrm{Fe}_{\mathrm{D}}^{*}$, respectively, for diazotrophs to survive (see Ward et al., 2013). This happens when $\phi_{\mathrm{PN}}$ and $\phi_{\mathrm{FeN}}$ are greater than a critical threshold slightly above one. The exact amount though will be dependent on the actual values of the sources $I_{\mathrm{P}}$ and $I_{\mathrm{Fe}}$ as well as diazotroph maximum growth rate and nutrient half saturation constant.

Numerical Model: we use model output to compute $\phi_{\mathrm{PN}}$ and $\phi_{\text {FeN }}$ (Fig. 5a and b). Here $I_{i}$ includes all advection and mixing into a model grid cell, remineralization of organic matter, and in the case of iron, dust and sedimentary sources.

For the most part the pattern of diazotrophy matches the regions where $\phi_{\mathrm{PN}}, \phi_{\mathrm{FeN}}>1$ (Fig. 5c). The threshold is, however, slightly larger than one (as a consequence of the slightly higher $\mathrm{Fe}^{*}$ and $\mathrm{P}^{*}$ for diazotrophs) and some regions 
Table 4. Theoretical framework.

\begin{tabular}{|c|c|c|}
\hline & Equations & $\#$ \\
\hline$\frac{\mathrm{dB}}{\mathrm{d} t}=$ & $\mu_{\mathrm{B}} \min \left(\frac{\mathrm{N}}{\mathrm{N}+\kappa_{\mathrm{NB}}}, \frac{\mathrm{P}}{\mathrm{P}+\kappa_{\mathrm{PB}}}, \frac{\mathrm{Fe}}{\mathrm{Fe}+\kappa_{\mathrm{FeB}}}\right) B-m_{\mathrm{B}} B$ & (1) \\
\hline$\frac{\mathrm{dD}}{\mathrm{d} t}=$ & $\mu_{\mathrm{D}} \min \left(\frac{\mathrm{P}}{\mathrm{P}+\kappa_{\mathrm{PD}}}, \frac{\mathrm{Fe}}{\mathrm{Fe}+\kappa_{\mathrm{FeD}}}\right) D-m_{\mathrm{D}} D$ & (2) \\
\hline \multirow[t]{2}{*}{$\frac{\mathrm{dN}}{\mathrm{d} t}=$} & $-\mu_{\mathrm{B}} \min \left(\frac{\mathrm{N}}{\mathrm{N}+\kappa_{\mathrm{NB}}}, \frac{\mathrm{P}}{\mathrm{P}+\kappa_{\mathrm{PB}}}, \frac{\mathrm{Fe}}{\mathrm{Fe}+\kappa_{\mathrm{FeB}}}\right) B$ & \\
\hline & $+I_{\mathrm{N}}-O_{\mathrm{N}}$ & (3) \\
\hline \multirow[t]{3}{*}{$\frac{\mathrm{dP}}{\mathrm{d} t}=$} & $-\mu_{\mathrm{B}} \min \left(\frac{\mathrm{N}}{\mathrm{N}+\kappa_{\mathrm{NB}}}, \frac{\mathrm{P}}{\mathrm{P}+\kappa_{\mathrm{PB}}}, \frac{\mathrm{Fe}}{\mathrm{Fe}+\kappa_{\mathrm{FeB}}}\right) R_{\mathrm{NP}_{\mathrm{B}}} B$ & \\
\hline & $-\mu_{\mathrm{D}} \min \left(\frac{\mathrm{P}}{\mathrm{P}+\kappa_{\mathrm{PD}}}, \frac{\mathrm{Fe}}{\mathrm{Fe}+\kappa_{\mathrm{FeD}}}\right) R_{\mathrm{NP}_{\mathrm{D}}} D$ & \\
\hline & $+I_{\mathrm{P}}-O_{\mathrm{P}}$ & (4) \\
\hline \multirow[t]{3}{*}{$\frac{\mathrm{dFe}}{\mathrm{d} t}=$} & $-\mu_{\mathrm{B}} \min \left(\frac{\mathrm{N}}{\mathrm{N}+\kappa_{\mathrm{NB}}}, \frac{\mathrm{P}}{\mathrm{P}+\kappa_{\mathrm{PB}}}, \frac{\mathrm{Fe}}{\mathrm{Fe}+\kappa_{\mathrm{FeB}}}\right) R_{\mathrm{NFe}_{\mathrm{B}}} B$ & \\
\hline & $-\mu_{\mathrm{BD}} \min \left(\frac{\mathrm{P}}{\mathrm{P}+\kappa_{\mathrm{PD}}}, \frac{\mathrm{Fe}}{\mathrm{Fe}+\kappa_{\mathrm{FeD}}}\right) R_{\mathrm{NFe}_{\mathrm{D}}} D$ & \\
\hline & $+I_{\mathrm{Fe}}-O_{\mathrm{Fe}}$ & (5) \\
\hline $\mathrm{N}_{\mathrm{B}}^{*}=$ & $\begin{array}{l}\text { Equilibrium Solutions } \\
\frac{\kappa_{\mathrm{NB}} m_{\mathrm{B}}}{\mu_{\mathrm{B}}-m_{\mathrm{B}}} \text { when } \mathrm{B} \text { is N limited }\end{array}$ & (6) \\
\hline $\mathrm{P}_{\mathrm{B}}^{*}=$ & $\frac{\kappa_{\mathrm{PB}} m_{\mathrm{B}}}{\mu_{\mathrm{B}}-m_{\mathrm{B}}}$ when $\mathrm{B}$ is $\mathrm{P}$ limited & (7) \\
\hline $\mathrm{Fe}_{\mathrm{B}}^{*}=$ & $\frac{\kappa_{\mathrm{FeB}} m_{\mathrm{B}}}{\mu_{\mathrm{B}}-m_{\mathrm{B}}}$ when $\mathrm{B}$ is $\mathrm{Fe}$ limited & (8) \\
\hline $\mathrm{P}_{\mathrm{D}}^{*}=$ & $\frac{\kappa_{\mathrm{PD}} m_{\mathrm{D}}}{\mu_{\mathrm{D}}-m_{\mathrm{D}}}$ when $\mathrm{D}$ is $\mathrm{P}$ limited & (9) \\
\hline $\mathrm{Fe}_{\mathrm{D}}^{*}=$ & $\frac{\kappa_{\mathrm{FeD}} m_{\mathrm{D}}}{\mu_{\mathrm{D}}-m_{\mathrm{D}}}$ when $\mathrm{D}$ is Fe limited & (10) \\
\hline $\mathrm{D}^{*}=$ & $\begin{array}{l}\frac{1}{m_{D} R_{\mathrm{NP}} \mathrm{D}}\left(\left(I_{\mathrm{P}}-O_{\mathrm{P}}\right)-R_{\mathrm{NP}_{\mathrm{B}}}\left(I_{\mathrm{N}}-O_{\mathrm{N}}\right)\right) \\
\text { when D limited by } \mathrm{P}\end{array}$ & (11) \\
\hline $\mathrm{D}^{*}=$ & $\begin{array}{l}\frac{1}{m_{D} R_{\mathrm{NFe}}}\left(\left(I_{\mathrm{Fe}}-O_{\mathrm{Fe}}\right)-R_{\mathrm{NFe}_{\mathrm{B}}}\left(I_{\mathrm{N}}-O_{\mathrm{N}}\right)\right) \\
\text { when D limited by Fe }\end{array}$ & (12) \\
\hline
\end{tabular}

where $\phi_{\mathrm{PN}}, \phi_{\mathrm{FeN}}$ are only slightly greater than one will not support diazotrophs (i.e. provinces II and IV).

In both the equatorial Atlantic and North Atlantic, $\phi_{\mathrm{PN}}$ is less than 1 (suggesting that no diazotrophs should exist) in regions where model diazotrophs are in fact present. In the equatorial Atlantic, advection and mixing from surrounding regions with diazotrophs support an immigrant population. The net growth rates of the diazotrophs in these regions, where the theorized $\phi_{\mathrm{PN}}$ is not sufficient, are negative and their population is maintained by transport from upstream (e.g. see Clayton et al., 2013). Similarly, the swift Gulf Stream current carries diazotrophs northward out of the regions that can support positive growth.

The model results as presented in Fig. 6a again suggest that the boundaries of provinces are largely, but not completely, controlled by $\phi_{\mathrm{FeN}}$ and $\phi_{\mathrm{PN}}$. Here each model grid cell is plotted as function of $\phi_{\mathrm{FeN}}$ and $\phi_{\mathrm{PN}}$ (Fig. 5) and colored by the province designation (Fig. 3). In the theory, province I should be in the top left quadrant, provinces II, III, IV and V in the top right quadrant, and VI in bottom
Table 5. Theoretical provinces. These descriptions of the provinces come from the framework outlined in Table 4 . No entry means there is no theoretical solution.

\begin{tabular}{lllllll}
\hline & $\mathrm{I}$ & $\mathrm{II}$ & $\mathrm{III}$ & $\mathrm{IV}$ & $\mathrm{V}$ & $\mathrm{VI}$ \\
\hline Ecosystem & & & & & & \\
Diazotrophs & no & no & yes & yes & no & no \\
Limiting diaz & - & - & $\mathrm{Fe}$ & $\mathrm{PO}_{4}$ & - & - \\
Limiting non-diaz & $\mathrm{Fe}$ & $\mathrm{N}$ & $\mathrm{N}$ & $\mathrm{N}$ & $\mathrm{N}$ & $\mathrm{P}$ \\
\hline Nutrient control & & & & & & \\
$\mathrm{N}$ & - & $\mathrm{N}_{\mathrm{B}}^{*}$ & $\mathrm{~N}_{\mathrm{B}}^{*}$ & $\mathrm{~N}_{\mathrm{B}}^{*}$ & $\mathrm{~N}_{\mathrm{B}}^{*}$ & - \\
$\mathrm{P}$ & - & - & - & $\mathrm{P}_{\mathrm{D}}^{*}$ & $>\mathrm{P}_{\mathrm{B}}^{*}$, & $\mathrm{P}_{\mathrm{B}}^{*}$ \\
$\mathrm{Fe}$ & $\mathrm{Fe}_{\mathrm{B}}^{*}$ & $>\mathrm{Fe}_{\mathrm{B}}^{*}$, & $\mathrm{Fe}_{\mathrm{D}}^{*}$ & - & - & - \\
& & $<\mathrm{Fe}_{\mathrm{D}}^{*}$ & & & & \\
\hline $\begin{array}{l}\text { Supply ratio } \\
\phi \mathrm{PN}\end{array}$ & - & $>1$ & $\gg 1$ & $>1$ & $>1$ & $<1$ \\
$\phi_{\mathrm{FeN}}$ & $<1$ & $>1$ & $>1$ & $\gg 1$ & $>1$ & - \\
\hline
\end{tabular}

right quadrant. The impact of transport is seen in the yellow dots (province IV) that have $\phi_{\mathrm{PN}}$ less than the hypothesized 1. However, all other provinces map well into the expected quadrants of the supply ratio phase space (see also Fig. 3 of Ward et al., 2013). Viewed in this resource supply ratio space, we can also see the anticipated nutrient controls (Fig. 6b, c, d) discussed in Sect. 3.2. For instance, iron is drawn down lowest (to $\mathrm{Fe}_{\mathrm{B}}^{*}$ ) in province I (top left quadrant), with an increased in concentration with increasing $\phi_{\mathrm{FeN}}$ into province II and III. In province III, iron will be maintained at $\mathrm{Fe}_{\mathrm{D}}^{*}$ which is greater than $\mathrm{Fe}_{\mathrm{B}}^{*}$. Where the iron is not ecological controlled (province IV, V, VI), the surface iron concentration is much higher. Similarly, we anticipate phosphate to be ecologically controlled (and thus drawn down low) in provinces IV, V, VI (part of top right and bottom right quadrants) and nitrate in provinces II, III, IV and V (top right quadrant).

\subsection{Nitrogen fixation}

Theory: the biomass of the diazotrophs is a function of the net excess rate of supply of $\mathrm{P}$ or $\mathrm{Fe}$ (whichever is liming) over $\mathrm{N}$, relative to the non-diazotroph elemental requirements (Eqs 11 and 12, Table 4). It is also a function of the diazotroph loss rates. In the theory we assume that the diazotrophs fix all the nitrogen that they require (though note that this assumption does not qualitatively change the results, see Dutkiewicz et al., 2009), and that all nitrogen goes to growth, such that $\mathrm{N}_{\mathrm{fix}}=\mu_{\mathrm{D}} \mathrm{D}$. In steady state this implies that nitrogen fixation is a function of both growth rate and the biomass of diazotrophs, which in turn is a function of the net excess supply of $\mathrm{P}$ or Fe. Thus we formally relate the rate of supply of excess $\mathrm{P}$ to nitrogen fixation, in accord with Gruber and Sarmiento (1997) and Deutsch et al. (2007), but 

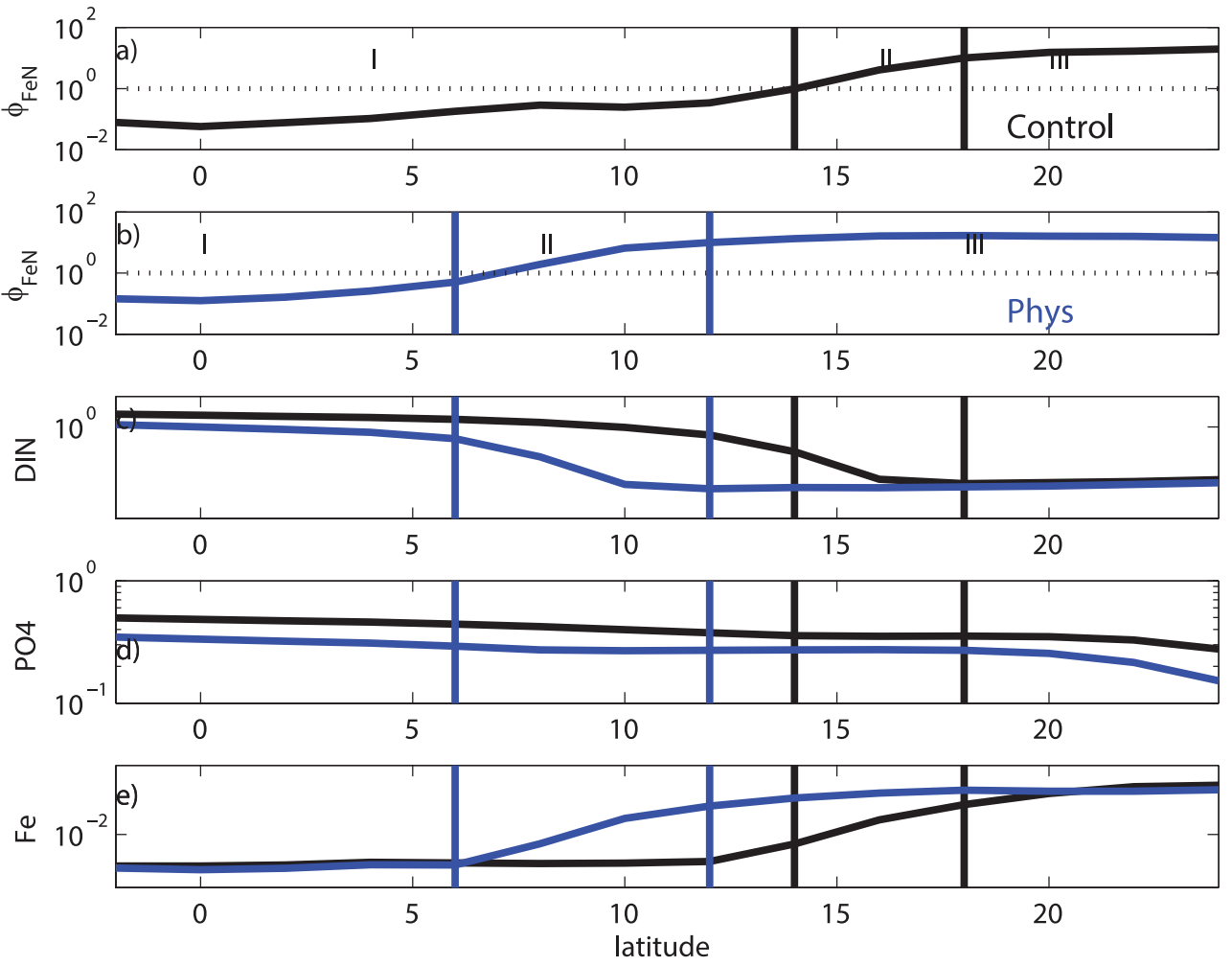

Figure 4. Model output from Pacific transect shown in Fig. 3. (a) $\phi_{\mathrm{FeN}}$ for control simulation; (b) $\phi_{\mathrm{FeN}}$ for Phys simulation with changes from a warming scenario at 2100; (c) DIN $\left(\mathrm{mmol} \mathrm{m}^{-3}\right)$; (d) $\mathrm{PO}_{4}\left(\mathrm{mmol} \mathrm{m}^{-3}\right)$; (e) iron $\left(\mu \mathrm{mol} \mathrm{m} \mathrm{m}^{-3}\right)$. Vertical lines indicate province boundaries as determined only by presence or absence of diazotrophs, and limiting nutrient(s). Province are labeled (I, II, III). Black line indicate results from Control, and blue lines from Phys.

also explicitly incorporate the role of excess iron supply. We note that the theory predicts relationships between fluxes of nutrients and not between nutrient concentrations. In particular, it does not suggest clear relationships between nitrogen fixation rate and iron or phosphate concentrations and indeed such relationships are not observed (Luo et al., 2014).

Numerical Model: we find that the diazotroph biomass and nitrogen fixation rates are related to the net excess supply of Fe or P (Fig. 6e, f): where there is excess supply of both nutrients (top, right quadrant) there is higher biomass and nitrogen fixation, and most grid cells in the other quadrants have zero (or very low) values. That some diazotroph are outside their prescribed provinces (discussed above) does lead to some scatter, but about $80 \%$ of both diazotroph biomass and nitrogen fixation rates do occur in the anticipated quadrant. However, even within the quadrant there is not a strong correlation between biomass/nitrogen fixation and net excess supply of $\mathrm{Fe}$ or $\mathrm{P}$. This is because both biomass and nitrogen fixation rates are also modulated by grazing pressure, and, in the case of nitrogen fixation, by diazotroph growth rate which is a function of temperature and light. Thus these scatter plots in terms of absolute excess in supply rates are not as clean as those in terms of supply resource ratio (Fig. 6a-d) used to describe diazotroph biogeography.

\section{A changing ocean}

We use the province framework to explain the resulting shifts in diazotroph biogeography seen in Fig. 2 . The theoretical considerations also provides insight into the movement of province boundaries and the implications for nutrient concentrations and nitrogen fixation.

\subsection{Shifts in provinces}

In Phys, we find a marked decrease in the supply of macronutrients $\left(I_{\mathrm{N}}\right.$ and $\left.I_{\mathrm{P}}\right)$ : increased stratification and slower overturning circulation lead to a reduction in the supply from the deep ocean. Moreover, increased primary production at the high latitudes (a response to higher temperatures and higher light with increased stratification, see Dutkiewicz et al., 2013) leads to higher consumption of nutrients at these latitudes and less makes it through mode and intermediate waters to lower latitudes (see e.g. Sarmiento et al., 2004). On the other hand, $I_{\mathrm{Fe}}$ changes are smaller as $I_{\mathrm{Fe}}$ is dominated by the atmospheric input (which stays at pre-industrial values in this experiment). As a consequence $\phi_{\mathrm{FeN}}$ is altered, increasing in many locations (Figs. 7a and $4 \mathrm{~b}$ ). We can summarize the subsequent changes to the province boundaries (Fig. 3b) relative to pre-industrial condition (Fig. 3a): 
a) $\phi_{\mathrm{PN}}$

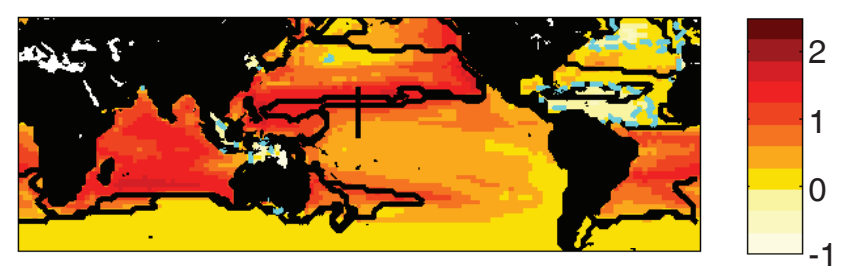

b) $\phi_{\mathrm{FeN}}$

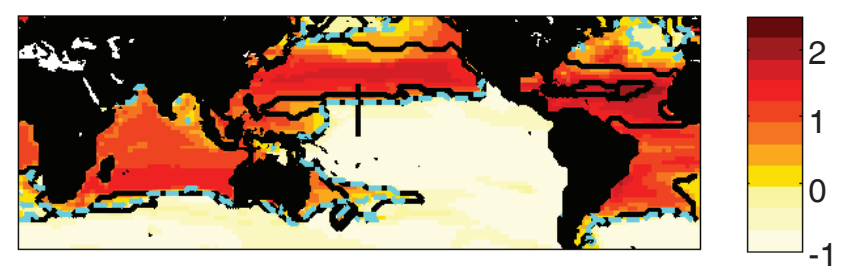

c) both $>1$

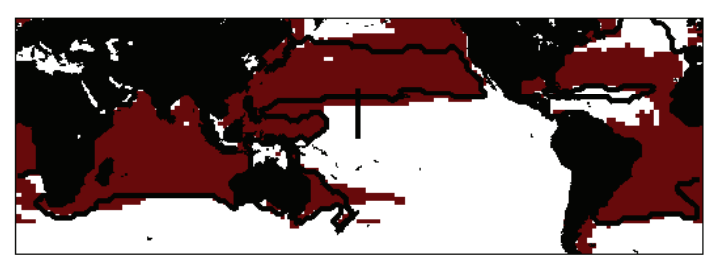

Figure 5. (a, b) Nutrient supply ratios (log unitless, annual average) into the surface $100 \mathrm{~m}$ of the numerical model for preindustrial conditions (experiment Control). (a) $\phi \phi_{\mathrm{PN}}=\frac{I_{\mathrm{P}}^{*}}{R_{\mathrm{NP}_{\mathrm{B}}} I_{\mathrm{N}}^{*}}$ and (b) $\phi_{\mathrm{FeN}}=\frac{I_{\mathrm{Fe}}^{*}}{R_{\mathrm{NFe}} I_{\mathrm{N}}^{*}}$. Dashed blue line bounds regions where both $\phi_{\mathrm{PN}}>1$ and $\phi_{\mathrm{FeN}}>1$ in (a). Black contours indicate the province boundaries in Fig. 3a. Black line in Pacific indicates the transect show in Figs. 4 and 8. (c) Brown shaded region indicates where both $\phi_{\mathrm{PN}}>1$ and $\phi_{\mathrm{FeN}}>1$, minimum conditions needed to support diazotrophs. Black contour indicates region which do have diazotrophs (compare to Fig. 1f).

- The $\phi_{\mathrm{FeN}}>1$ area increases (blue line in Figs. 7a and $2 b)$ and therefore province II and III expand at the expense of province I, particularly in the Pacific (Fig. 4b).

- A decrease in phytoplankton biomass in the North Atlantic (a consequence of reduced macronutrient supply, which are limiting here), leads to accumulation of unused iron (Dutkiewicz et al., 2012). Consequent higher horizontal gradients of iron lead to an increase in $I_{\mathrm{Fe}}$ to downstream areas and consequent large increase in $\phi_{\mathrm{FeN}}$ in this region. Province IV (where $\phi_{\mathrm{FeN}} \gg 1$, see Table 5 and Sect. 3.3) therefore increases: diazotrophs become phosphate limited in more regions.

- The large increase in $\phi_{\mathrm{FeN}}$ also leads to a reduction in the area of province V (no diazotrophs) in the North Atlantic.
In HiIron we also find an increase in regions where $\phi_{\mathrm{FeN}}>$ 1 (Fig. 7b). The increased supply of iron and a small biologically driven decrease in DIN supply (due to higher productivity, especially at higher latitudes) leads to an increased $\phi_{\mathrm{FeN}}$ and is enough to allow accumulation of $\mathrm{Fe}$ to $\mathrm{Fe}_{\mathrm{D}}^{*}$. We find very similar (though more severe) changes to the province boundaries as in Phys: expansion of province II and III at the expense of I in the Pacific (Fig. 8). In the Atlantic, doubling of the highest dust deposition leads to $\phi_{\mathrm{FeN}} \gg 1$ and province IV expands and V shrinks (Fig. 3c). Here, though the response is similar to Phys, the underlying reason is different: decreased biomass consuming iron in Phys vs. increased iron input in HiIron. We also find a region in the North Pacific where $\phi_{\mathrm{FeN}}$ become large enough that a region switches from province III to IV (diazotrophs shift from being iron limited to phosphate limited).

The biogeographical distribution of diazotrophs increases in both Phys (17\%) and HiIron (38\%) (Table 2).

\subsection{Changes to nutrient concentrations}

There are changes to the nutrient concentration in Phys after 100 years of warming relative to pre-industrial conditions (Control). In general the macronutrients (DIN and phosphate) concentrations decrease over the course of the projected 21 st century, but iron has a more complex pattern of increase and decrease (Fig. 4c-e).

We can partition the nutrient concentration changes into those that occur because the province boundaries change, and those that occur as a consequence of changes within provinces to the non-limiting, or limiting nutrients:

- When boundaries shift in the warming scenario, some nutrients change from being ecologically controlled to "free" (or vice versa). This can lead to large changes in concentration (e.g. Fe in Fig. 4e).

- Within provinces non-ecologically controlled nutrients can also have large changes (e.g. DIN in province I, Fig. 4c, and phosphate in provinces I, II, and III Fig. 4d): changes in supply, or to changes in biomass (and thus consumption of the nutrients) leads to these shifts.

- We also find small decreases in the ecologically controlled nutrients even within provinces (e.g. lower DIN in provinces III, and lower iron in provinces I and III). The growth rate of all the phytoplankton is parameterized to increase as temperatures warm (Eppley, 1972). These higher growth rate, $\mu_{j}$ in Phys will lead to lower values to which the limiting nutrient is drawn down (Eqs. 6-10) by 2100 .

We reinforce this latter result with an additional experiment (Phys-Temp, see Appendix A and Table 1) where we allow only the growth rates to change with increasing temperature to 2100 (circulation, and hence macronutrient supply, remains as pre-industrial). We found the same small de- 

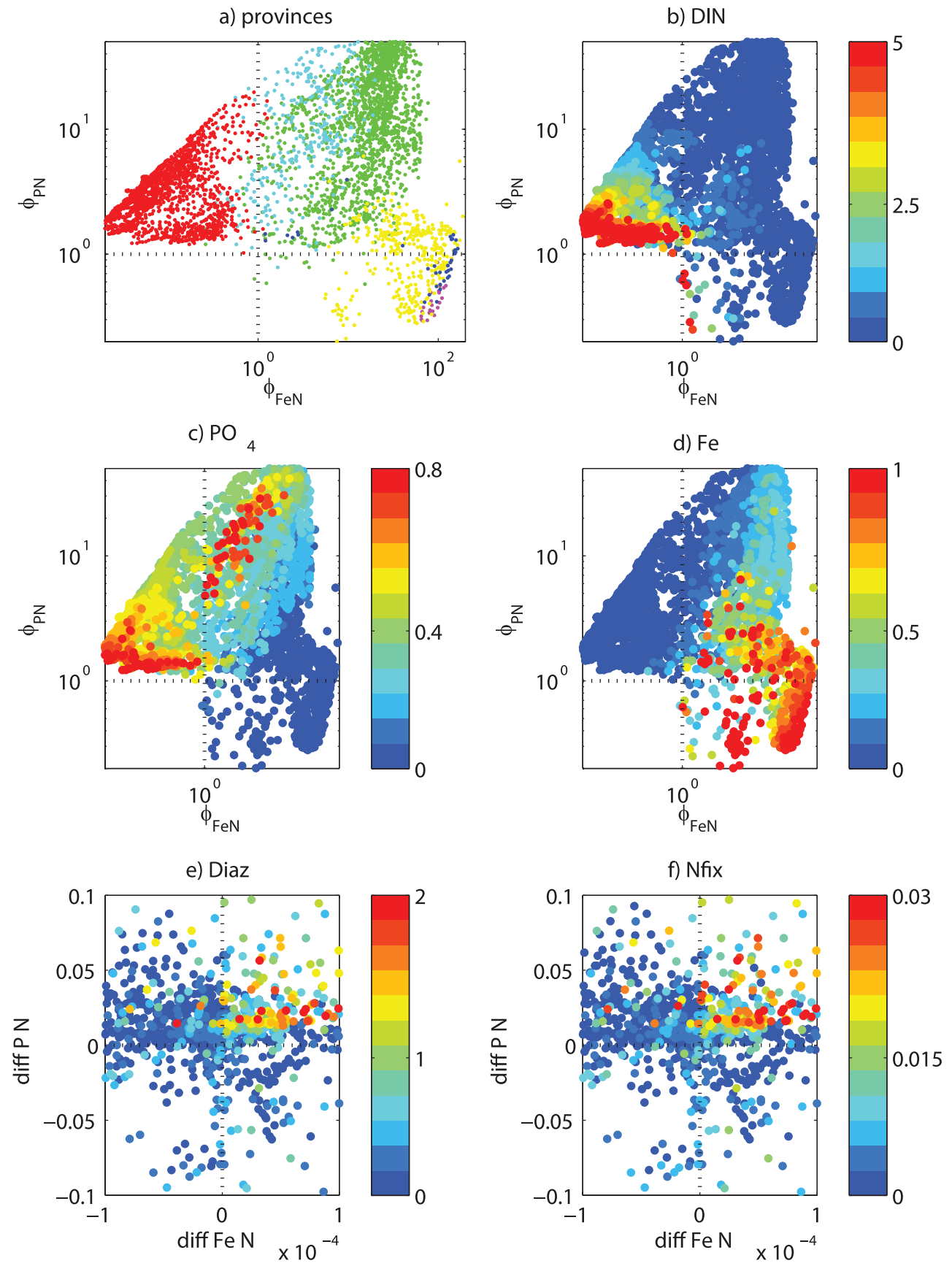

Figure 6. Scatter plots for pre-industrial conditions (experiment Control). Each model grid cell is plotted as function of its annual averaged (a-d) supply rate ratio $\phi_{F e N}$ and $\phi_{P N}$ or $(\mathbf{e}, \mathbf{f})$ excess Fe, $\mathrm{P}$ supply rate $\left(\left(I_{\mathrm{Fe}}-O_{\mathrm{Fe}}\right)-R_{\mathrm{NFe}_{\mathrm{B}}}\left(I_{\mathrm{N}}-O_{\mathrm{N}}\right)\right)$ and $\left(\left(I_{\mathrm{P}}-O_{\mathrm{P}}\right)-R_{\mathrm{NP}}\left(I_{\mathrm{N}}-O_{\mathrm{N}}\right)\right)$. (a) Province designation in same colors as in Figure 3 (except for VI which is colored magenta here); (b) concentration of DIN in the top $100 \mathrm{~m}(\mu M)$; (c) phosphate $(\mu M)$; (d) iron $(\mathrm{nM})$; (e) diazotroph biomass $\left(\log \mathrm{g} \mathrm{C} \mathrm{m}^{-3}\right)$; and (f) nitrogen fixation rate $\left(\log \mathrm{g} \mathrm{N} \mathrm{m}^{-2} \mathrm{yr}^{-1}\right)$. Dotted lines indicate $\phi_{F e N}=1$ and $\phi_{P N}=1$ in (a-d) and $\left(\left(I_{\mathrm{Fe}}-O_{\mathrm{Fe}}\right)-R_{\mathrm{NFe}_{\mathrm{B}}}\left(I_{\mathrm{N}}-O_{\mathrm{N}}\right)\right)=0$ and $\left(\left(I_{\mathrm{P}}-O_{\mathrm{P}}\right)-R_{\mathrm{NP}}\left(I_{\mathrm{N}}-O_{\mathrm{N}}\right)\right)=0$ in (e,f).

crease in the ecologically controlled nutrients in all province as in Phys, but virtually no changes to non-ecologically controlled nutrients. Thus higher growth rates lead to lower $\mathrm{Fe}^{*}$,
$\mathrm{P}^{*}, \mathrm{~N}^{*}$ and ambient ecologically controlled limiting nutrients are drawn down further in this warmer world.

In HiIron we find (Fig. 8) that the nutrient that is ecologically controlled in a given province has virtually no change in 
a) Phys (2100)
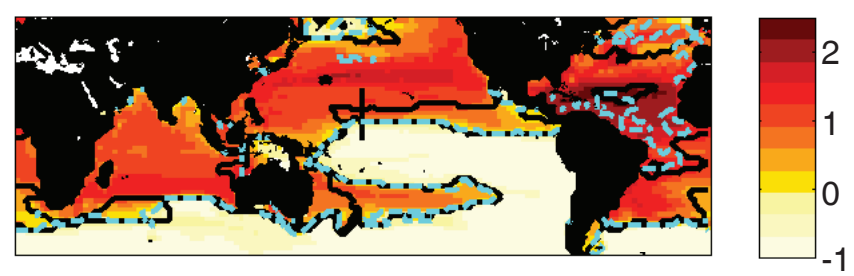

b) Hilron
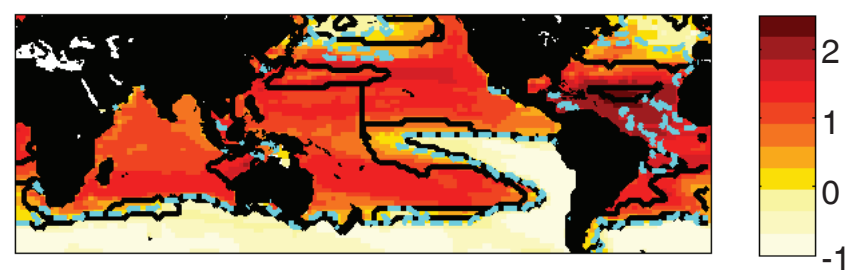

Figure 7. Iron to nitrogen supply ratio, $\phi_{\mathrm{FeN}}=\frac{I_{\mathrm{Fe}}^{*}}{R_{\mathrm{NF}_{\mathrm{B}}} I_{\mathrm{N}}^{*}}(\log$ unitless, annual average) (a) 2100 conditions if physical fields, including ocean temperatures change in a business as usual emission scenario but with pre-industrial iron dust supply (experiment Phys); (b) conditions if physical fields remain as for pre-industrial, but iron dust supply is doubled (experiment HiIron). Black contours indicate the province boundaries in Fig. $3 \mathrm{~b}$ and c. Dashed blue line bounds regions where both $\phi_{\mathrm{PN}}>1$ and $\phi_{\mathrm{FeN}}>1$ in each experiment.

concentration relative to the pre-industrial experiment Control. For example DIN and Fe do not change in regions which remain in province III. There are changes in the non-limiting, non-ecologically controlled nutrient in the provinces as a response to increased dust (in the case of iron) or phytoplankton biomass changes (in the case of the macronutrients). Lower DIN and $\mathrm{PO}_{4}$ in the equatorial Pacific (Fig. 8) is due to the higher biomass. The biggest changes in concentrations occur in the those regions that were within one province in Control and in another in HiIron; for instance iron increases most in the regions of the Pacific that were province I in Control and province II or III in HiIron.

\subsection{Nitrogen Fixation}

In both sensitivity studies there is also an increase in the globally integrated nitrogen fixation rate (17\% for Phys and $28 \%$ for HiIron, Table 2). In HiIron, the increase in biogeographical area and the increase in net excess supply of iron relative to the non-diazotroph needs leads to mostly higher local nitrogen fixation. However, some areas become phosphate limited and have a reduction instead (e.g. areas which switch from province III to IV). But globally the net increase of Fe supply relative to nitrate leads to enhanced nitrogen fixation.

Further sensitivity studies (see Table 1 and Appendix A) show that the situation in Phys is more complicated. In experiment Phys-Temp the growth rates of all the phytoplankton increase as a consequence of higher temperatures (follow- ing Eppley, 1972) over the course of the 21st Century, but the circulation (and hence the supply of nutrients) remained as pre-industrial. Here we find only a small increase in diazotroph biogeography (Table 2), but a large (18\%) increase in nitrogen fixation: as they grew faster in warmer water the diazotrophs fixed more nitrogen. In the converse experiment (Phys-Circ), temperatures affecting growth were held at preindustrial levels, but the circulation (and hence macronutrient supply rates) changed as for the warming scenario. Here, though the diazotroph regions increased (14\%), there was no increase in global nitrogen fixation. Reduction in phosphate supply led to more areas being phosphate limited, and little change in the net excess supply of phosphate relative to the non-diazotroph needs leads to lower nitrogen fixation. Thus in the full experiment Phys it is primarily the temperature increases, not the regional increases in diazotrophy, that led to the increase in nitrogen fixation. Globally integrated results for the change in the nitrogen fixation rates will therefore be sensitive to the parametrization of phytoplankton growth with changing temperature. The changes to primary production (Table 2) are also dependent on the temperature parameterization (see Dutkiewicz et al., 2013 for further discussion on primary production changes).

\section{Discussion: implications and limitations}

We have demonstrated the value of resource-ratio framework for interpreting complex simulations of global change scenarios. Essential assumptions of the theoretical framework are that the diazotrophs grow slower than other phytoplankton and that they are never nitrogen limited. The former has good empirical support (e.g. Berman-Frank et al., 2001) and the latter is reasonable since they can fix the abundant nitrogen gas. A third, though not essential assumption, that we make in the theoretical framework is that diazotrophs require more iron than other phytoplankton (also supported empirically, e.g., Berman-Frank et al., 2001; Kustka et al., 2003).

The results from our simulations, increased diazotroph geographic range, in both higher iron supply or a warming ocean were not a priori understood without the simpler theoretical framework. The parameterizations in the numerical simulation made the same assumptions as discussed above for diazotroph growth, iron needs and ability to fix all required nitrogen. However, the numerical simulation included additional nutrient constraints, several diazotroph and nondiazotroph species, grazers as well as full three-dimensional transport and mixing. The numerical simulations were never in steady state. However, as suggested by our previous studies (e.g. Dutkiewicz et al., 2009, 2012), we find that the theoretical framework provided crucial insight into the results of the numerical model at the low latitude regions where diazotrophs typically occur (Luo et al., 2012).

The assumptions on growth, iron needs and ability to fix nitrogen have also been made in parameterization of di- 

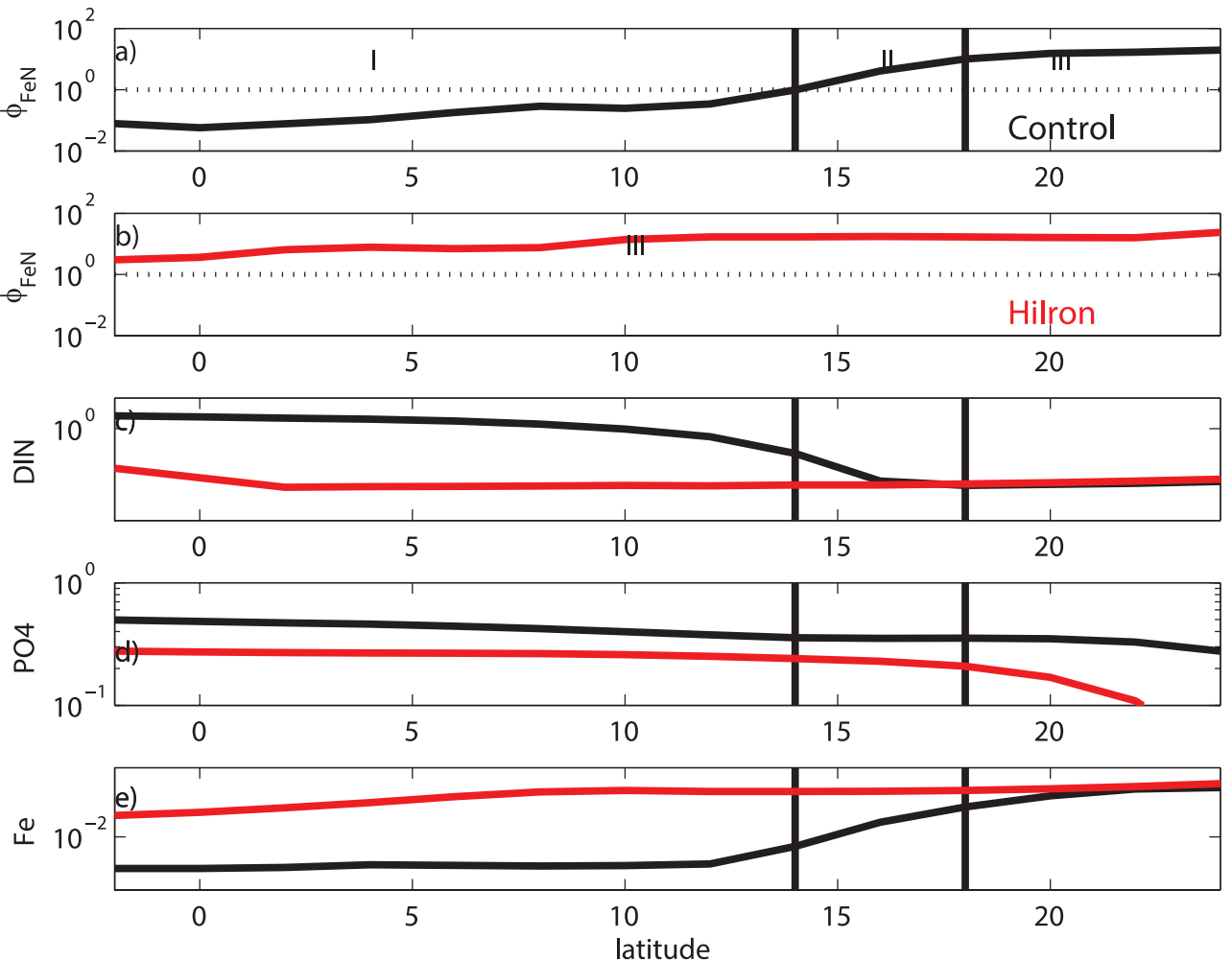

Figure 8. Model output from Pacific transect indicated in Fig. 3. (a) $\phi_{\mathrm{FeN}}$ for control simulation; (b) $\phi_{\mathrm{FeN}}$ for HiIron simulation with doubled dust; (c) DIN ( $\left.\mathrm{mmol} \mathrm{m}^{-3}\right)$; (d) $\mathrm{PO}_{4}\left(\mathrm{mmol} \mathrm{m}^{-3}\right)$; (e) iron $\left(\mu \mathrm{mol} \mathrm{m}^{-3}\right)$. Vertical lines indicate province boundaries as determined only by presence or absence of diazotrophs, and limiting nutrient(s). Province labeled (I, II, III). Black lines indicate results from Control, and red lines from HiIron; the whole transect is province III in Hilron (see Fig. 3c)

azotrophs in many other recent marine ecosystem models (e.g. Coles et al., 2007; Krishnamurphy et al., 2009; Le Quéré et al., 2005; including many involved in the Coupled Model Intercomparison Project 5). We suggest, therefore, that our framework could provide a useful tool to interpret intermodel differences in diazotroph distributions and changes in future climate scenarios.

The framework suggests that diazotroph biogeography will change with alterations to the supply rates of $\mathrm{Fe}$ and $\mathrm{P}$ relative to that of DIN. An increase in $\phi_{\mathrm{FeN}}$ (whether through reduction in DIN supply or an increase in Fe supply) will lead to an increased region supporting diazotrophy. We suggest that calculation of $\phi_{\mathrm{FeN}}$ in other model studies of climate change will be able to help explain changes in diazotroph distribution.

The framework also suggests that the change in nitrogen fixation rates will be related to the changes in diazotroph growth rates and to alterations in the net excess supply of phosphate or iron relative to the non-diazotroph needs. The changes in the numerical model are also modulated by how temperature alters growth rates and the intensity of the grazing.

Though the theoretical framework specifically uses nutrient supply ratios to predict diazotroph biogeography (pres- ence/absence), and the nutrient supply differences to suggest nitrogen fixation rates, it also suggests patterns of nutrient concentrations dictated from the province perspective. In particular, the model suggests that in any province, the locally limiting nutrient will be uniformly drawn down to a low, subsistence concentration. Thus, we do not anticipate any correlation between nutrient concentrations themselves and diazotroph biomass or nitrogen fixation: indeed no such correlation was found in the study of Luo et al. (2014) which looked a compilation of observed nitrogen fixation and observed nutrient concentrations. The theory suggests that strong gradients of nutrient concentrations occur between provinces. The theoretical predictions are consistent with the strong transitions in surface phosphate, iron and fixed nitrogen concentrations, as well as the distribution of diazotrophs, observed along the Atlantic Meridional Transect (Moore et al., 2009; Ward et al., 2103).

The resource supply ratio framework provides a useful tool for interpreting and synthesizing the shifts in province boundaries, and attendant changes in these sharp nutrient gradients, in the climate change simulations. Local changes from a very low to a high concentration in the surface concentration of a particular nutrient typically reflects a transition away from ecological control (and visa versa). Thus 
the movement of these sharp transitions in surface nutrient concentrations provides a simple measure of the shifting province boundary. Consistently, Schlosser et al. (2013) connected the observed movement of the sharp gradients between high and low surface iron concentrations and the internannual changes in the aeolian iron supply in the Atlantic.

We suggest that the sharp gradients in surface nutrient concentrations associated with the province boundaries provide a relatively simple metric by which to monitor shifts both in numerical simulations and in nature. Changes in nutrient concentrations will be a much simpler measure of the shifting boundary than the changes in the supply ratio that are actually responsible for the shift. Provided it is applied appropriately to sharp gradients associated with actual boundaries (and not indiscriminately to any nutrient gradient), this simple metric reflects complex underlying ecological dynamics. We note that the resource-ratio perspective is not likely to be useful in strongly seasonal regimes.

There are additional process that may affect the changes in nutrient supply that we have not addressed, such as slow temporal shifts in dust supply, changes in aeolian deposition of nitrate and phosphate, and changes in iron chemistry in a more acidic ocean (Shi et al., 2010). It is not, in fact, clear how iron dust supply will change in the future (Mahowald and Luo, 2003; Tegen et al., 2004), so we have discussed here a hypothetical doubling iron dust deposition scenario. We did, however, also conduct a half iron deposition experiment (LoIron, see Tables 1 and 2) with anticipated opposite response. The future ocean is likely to experience a change in supply of both macronutrients and iron dust. We have conducted additional studies that consider changes to both (Phys + Hilron, Phys + LoIron $)$ which indicate that the two effects can cancel or enhance each other depending on how relative supply rates change.

We have not considered the many other changes that will certainly effect phytoplankton. Increased ocean acidification may change cellular stoichiometry (Riebesell et al., 2007; Finkel et al., 2010) with consequences to nitrogen fixation (Tagliabue et al., 2011). Higher $\mathrm{CO}_{2}$ appears to increase growth rates of diazotrophs, in particular Trichodesmium (Levitan et al., 2007; Hutchins et al., 2013). Such changes are also likely to affect diazotroph biogeography and global nitrogen fixation rates in a future world. We believe that with modifications our theoretical framework will provide insight into changes that will occur from other alterations to the physical, chemical and grazing controls that may occur due to climate change.

The theory and numerical model have additionally only considered autotrophic diazotrophs and not addressed all the likely controls on diazotroph biogeography and nitrogen fixation. In some regions of the ocean nitrogen fixation may be dominated by heterotrophic diazotrophs (e.g. South Pacific, Halm et al., 2012). Symbiotic nitrogen fixers may fix more than their own requirements (e.g. Foster et al., 2011). High oxygen may limit nitrogen fixation (e.g. Staal et al., 2007). These issues have not been taken into account in this paper.

Recent studies have suggested the importance of variable phytoplankton stoichiometry in setting patterns of diazotrophy (Mills and Arrigo, 2010; Weber and Deutsch, 2012). The numerical model used here has fixed stoichiometry. Results with a variable stoichiometry model will certainly change the details of the results. However, given the several orders of magnitude in the changes in $\phi_{\mathrm{FeN}}$, we suggest that the largescale results from this study will be robust. Ward et al. (2013) conducted a sensitivity study to show that though the boundaries did shift with different assumption of cellular elemental ratios, the broad-scale patterns remained robust. Certainly, though, a next step in this province framework is to incorporate variable stoichiometry.

\section{Conclusions}

We have applied a resource-ratio framework to an interpretation of the controls on tropical and subtropical surface ocean nutrients and diazotroph biogeography and, in particular, how these may change in a series of experiments representing processes that may occur in a future world.

We outlined distinct provinces determined by the biogeography of diazotrophs and the nutrients that limit the community. The province boundaries are dictated by the relative supply of $\mathrm{Fe}$ and $\mathrm{P}$ relative to DIN. Our sensitivity experiments suggest that the most vulnerable regions to province shifts are the equatorial Pacific and the outer edge of the South Pacific gyre, as well as the the central Atlantic, in particular the central North Atlantic gyre. In these regions we suggest that diazotrophs may have a more favorable environment in a future world with lower macronutrient supply and/or higher iron dust supply.

It is the relative change in nutrient supplies which regulate province shifts. We find similar changes to the distribution of the diazotrophs whether we increased iron supply or decreased nitrate supply: it was the ratio of the two that was important. The theory lays out nicely how the ratio of the nutrient supply dictates the diazotroph biogeography. The absolute changes in the net excess supply of the limiting nutrient and the alteration to the diazotroph maximum growth rate (e.g. through increase temperature) determines the shifts in nitrogen fixation rates.

Our analysis suggests that a potentially sensitive and powerful indicator of global change is the shifting of the transition regions in nutrient concentrations which mark the boundaries of the provinces. Because of this connection, such changes would provide powerful inferences about complex biogeochemical cycles from a relatively simple observed indicator. Resource-ratio theory provides the framework to make such interpretations. The position of surface nutrient transitions could, perhaps, be monitored using underway instruments on ships of opportunity. A good prior mapping of 
which nutrient gradients denote current provinces will be important to ascertain before major changes occur. The theory has indeed already been used to identify short-term shifts in province boundaries (Schlosser et al., 2013).
Without a consistent conceptual framework, models make uncertain and often conflicting predictions. The resource supply ratio framework applied here helps us to understand the results of the more complex numerical model, and provides insight to mechanisms at play in the real ocean. We suggest that the province analysis would be helpful in understanding other numerical models (e.g. those used in the IPCC) and a helpful tool in understanding the differences in responses between models. An understanding of the controls on distinct ecological and biogeographical provinces will help us anticipate changes and understand observed changes in a future warmer world. 


\section{Appendix A: Additional numerical model description}

The MIT Integrated Global Systems Model (IGSM) (Dutkiewicz et al., 2005; Scott et al., 2008; Sokolov et al., 2009; Dutkiewicz et al., 2013) has a three-dimensional ocean circulation component (MITgcm, Marshall et al., 1997) embedded in it. In this study the ocean has horizontal resolution of $2^{\circ} \times 2.5^{\circ}$ and 22 vertical levels ranging from $10 \mathrm{~m}$ in the surface to $500 \mathrm{~m}$ at depth. Ocean boundary layer physics is parameterized using the KPP formulation (Large et al., 1994) and the effects of mesoscale eddies, not captured at this coarse resolution, is parameterized (Gent and McWilliams, 1990). The carbon cycle in these simulations is parameterized as in Dutkiewicz et al. (2005).

The coupled system is spun up for 2000 years (using 1860 conditions) before simulating 1860 to 2100 changes. Atmospheric greenhouse gas and volcanic observations are specified from 1860 to 2000; for the 21st century we use human emissions for a "business and usual" scenario that is projected by an economics module (Sokolov et al., 2009). This scenario is constructed under the assumption that no climate policies are imposed over the 21 st century, and is similar to the Representative Concentration Pathways 8.5 (RCP8.5) used in the Coupled Model Intercomparison Project 5 (CMIP5).

We use the physical ocean fields from the IGSM simulation to drive an ocean biogeochemistry and ecosystem model (see Dutkiewicz et al., 2009, 2012, 2013; Hickman et al., 2010 for full description and parameter values). Different from our earlier studies, this model includes explicit treatment of Chlorophyll such that the $\mathrm{Chl}: \mathrm{C}$ ratio is dynamic following Geider et al. (1998). Phytoplankton growth rate is a function of the $\mathrm{Chl}: \mathrm{C}$, temperature, light and nutrient availability (Geider et al., 1998) as done in Hickman et al. (2010). Iron chemistry includes explicit complexation with an organic ligand, scavenging by particles (Parekh et al., 2005) and representation of aeolian (Luo et al., 2008) and sedimentary (Elrod et al., 2004) sources. Nitrogen fixation is treated as in Monteiro et al. (2010) and Dutkiewicz et al. (2012). However, an improvement over those studies is inclusion of explicit water column denitrification parameterized such that nitrate is consumed during remineralization of organic matter rather than oxygen when oxygen drops below $4 \mu \mathrm{M}$. Stoichiometry of denitrification follows Anderson (1995).

We resolve several non-diazotroph types of phytoplankton (analogues of diatoms, coccolithophores, other large eukaryotes, Prochlorococcus, and other pico-phytoplankton), as well as two diazotroph types (analogues of Trichodesmium and unicellular types, following Monteiro et al., 2010). There are two grazers classes. The biogeochemical and biological tracers are transported and mixed by the climate system model, and interact through the formation, transformation and remineralization of organic matter. Excretion and mortality transfer living organic material into sinking particulate and dissolved organic detritus which are respired back to inorganic form.

The ecosystem model is quasi-spunup (240 years) with pre-industrial (1860) physical conditions and aeolian iron dust supply (Luo et al., 2008). From these initial conditions, we conduct a series of experiments (Table 1) (similar to those in Dutkiewicz et al., 2013):

1. Control. For another 240 years, we use pre-industrial (1860) physical conditions and aeolian iron dust supply (Luo et al., 2008).

2. Phys. For 240 years, the system is perturbed with changes to the physical ocean (temperature, circulation and mixing) as a result of increasing greenhouse gases in the "business as usual" described above. Iron dust supplies are maintained at pre-industrial values (Luo et al., 2008).

3. HiIron. For 240 years, the model is run with dust deposition doubled from pre-industrial, but the physical state remains as for pre-industrial conditions (as in Control).

4. Phys-Temp. For 240 years, the system is perturbed with biological rates that change according to temperatures from the "business as usual" scenario, but circulation, mixing and dust supply remain as for pre-industrial conditions.

5. Phys-Circ. For 240 years, the system is perturbed with circulation and mixing changing for the "business as usual" scenario, but the temperatures affecting biological rates remain as for pre-industrial conditions.

6. Phys+HiIron. As for Phys, but with doubled iron deposition rates.

7. LoIron. For 240 year, the model is run with dust deposition halved from pre-industrial, but physical state remain for pre-industrial conditions.

8. Phys +LoIron. As for Phys, but with half iron deposition rates.

The results discussed in this article all come from the last 5 years of these simulations - in the case of Phys this would be equivalent to the calendar years 2095-2100.

In the main text we focus on only two of these experiments (Phys and HiIron) as these illustrate most of the relevant points. The separation of circulation vs. temperature effects (Phys-Circ and Phys-Temp) are also useful to explain the global implication of the biogeography changes. 


\section{Appendix B: More on theoretical framework}

Our theoretical framework (Tables 3 and 4) is based on resource competition (Tilman, 1982). It builds directly on our earlier studies Dutkiewicz et al. (2012) and Ward et al. (2013). Dutkiewicz et al. (2012) only considered two nutrients (nitrate and iron). Ward et al. (2013) included phosphate into the theory, but assumed a more simplified representation of nutrient supply (considering only supply from deep water and, in the case of iron, from dust). Here we consider a more detailed treatment of the nutrient supplies.

By manipulating Eqs. (3-5) (Table 4) in equilibrium, we also obtain relationships for the relative ratio of the supply of nutrients, normalized by the elemental stoichiometry of the non-diazotrophs: $\phi_{\mathrm{PN}}=\frac{I_{\mathrm{P}}^{*}}{R_{\mathrm{NP}_{\mathrm{B}}} I_{\mathrm{N}}^{*}}$ and $\phi_{\mathrm{FeN}}=\frac{I_{\mathrm{Fe}}^{*}}{R_{\mathrm{NF}_{\mathrm{B}}} I_{\mathrm{N}}^{*}}$.

$$
\begin{array}{rr}
\phi_{\mathrm{PN}}= & 1+\frac{m_{\mathrm{D}} D R_{\mathrm{NP}_{\mathrm{D}}}}{R_{\mathrm{NP}_{\mathrm{B}}} I_{\mathrm{N}}^{*}}+\frac{O_{\mathrm{P}}-O_{\mathrm{N}} R_{\mathrm{NP}_{\mathrm{B}}}}{R_{\mathrm{NP}_{\mathrm{B}}} I_{\mathrm{N}}^{*}} \\
\phi_{\mathrm{FeN}}= & 1+\frac{m_{\mathrm{D}} D R_{\mathrm{NFe}_{\mathrm{D}}}}{R_{\mathrm{NFe}_{\mathrm{B}}} I_{\mathrm{N}}^{*}}+\frac{O_{\mathrm{Fe}}-O_{\mathrm{N}} R_{\mathrm{NFe}_{\mathrm{B}}}}{R_{\mathrm{NFe}_{\mathrm{B}}} I_{\mathrm{N}}^{*}}
\end{array}
$$

Since this representation is different from our earlier studies, we discuss it further. (Though we note that the conclusions are similar to those earlier studies.) These expressions are made up of three terms. The second term is only nonzero (and positive) when there are diazotrophs (province III and IV). The third term is dictated by sink terms which will be dominated by transport. However, in the equilibrium assumption if a nutrient is under ecological control, most excess input is taken into biomass and $O_{i} \approx 0$. Thus $O_{\mathrm{N}} \approx 0$ in provinces II-V, $O_{\mathrm{Fe}} \approx 0$ in I and III, and small in II, $O_{\mathrm{P}} \approx 0$ in IV and VI and small in V. We can therefore determine where the third term in each of Eqs. (11) and (12) are positive or negative and hence whether $\phi_{\mathrm{PN}}$ and $\phi_{\mathrm{FeN}}$ are greater than or less than 1 (see Table 2). For instance in province I, with $O_{\mathrm{Fe}} \approx 0$ and $O_{\mathrm{N}}>0, \phi_{\mathrm{FeN}}<1$. The boundary between province I and II occurs when $\phi_{\mathrm{FeN}}=1$ (i.e. when $O_{\mathrm{N}}$ also approaches zero as $\mathrm{N}$ becomes ecologically controlled). Across province II as $\phi_{\mathrm{FeN}}$ increases, Fe increases until it reaches $\mathrm{Fe}_{\mathrm{D}}^{*}$ at which point diazotrophs can coexist and the province boundary between II and III is reached. Here the second term in Eq. (12) is now positive (this excess iron is utilized by the diazotrophs), but the third term is zero. In province IV, the second term is still positive, iron is no longer ecologically controlled such that the third term is also positive and $\phi_{\mathrm{FeN}}$ is large. Similarly changes in $\phi_{\mathrm{PN}}$ occur moving from VI to V and so on. See the Web Appendix of Ward et al. (2013) for a more detailed theoretical description of these provinces. 
Acknowledgements. This work was supported in part by grant DE-FG02-94ER61937 from the US Department of Energy, Office of Science, grant OCE-1048926 (MOBY) from the National Science Foundation, grant OCE-1259388 from the National Science Foundation, and by grant NA09OAR4310069 from the National Oceanic and Atmospheric Administration. Additional funding was provided by the industrial and foundation sponsors of the MIT Joint Program on the Science and Policy of Global Change (see http://globalchange.mit.edu/sponsors/all). We thank N. Gruber and Y.-W. Luo for helpful comments on this manuscript.

Edited by: E. Marañón

\section{References}

Anderson, L.: On the hydrogen and oxygen content of marine phytoplankton, Deep-Sea Res. Pt. I, 42, 1675-1680, 1995.

Berman-Frank, I., Cullen, J. T., Shaked, Y., Sherrell, R. M., and Falkowski, P. G.: Iron availability, cellular iron quotas, and nitrogen fixation in Trichodesmium, Limnol. Oceanogr., 46, 12491260, 2001.

Bopp, L., Monfray, P., Aumont, O., Dufresne, J.-L., Le Treut, H., Madec, G., Terray, L., and Orr, J. C.: : Potential impact of climate change on marine export production, Global Biogeochem. Cy., 15, 81-99, 2001.

Clayton, Dutkiewicz, S., Jahn, O., and Follows, M. J.: Ocean eddies and dispersal maintain phytoplankton diversity, Limnol. Oceanogr., 3, 182-199, doi:10.1215/21573689-2373515, 2013.

Coles, V. J. and Hood, R. R.: Modeling the impact of iron and phosphorus limitations on nitrogen fixation in the Atlantic Ocean, Biogeosciences, 4, 455-479, doi:10.5194/bg-4-455-2007, 2007.

Deutsch, C., Sarmiento, J. L., Sigman, D. M., Gruber, N., and Dunne, J. P.: Spatial coupling of nitrogen inputs and losses in the ocean, Nature, 455, 163-167, doi:10.1038/nature05392, 2007.

Dutkiewicz, S., Sokolov, A., Scott, J., and Stone, P.: A ThreeDimensional Ocean-Sea-Ice-Carbon Cycle Model and its Coupling to a Two-dimensional Atmospheric Model: Uses in Climate Change Studies, Report 122, Joint Program of the Science and Policy of Global Change, MIT, Cambridge, MA, 2005.

Dutkiewicz, S., Follows, M. J., and Bragg, J.: Modeling the coupling of ocean ecology and biogeochemistry, Global Biogeochem. Cy., 23, GB1012, doi:10.1029/2008GB003405, 2009.

Dutkiewicz, S., Ward, B. A., Monteiro, F., and Follows, M. J.: Interconnection between nitrogen fixers and iron in the Pacific Ocean: theory and numerical model, Global Biogeochem. Cy., 26, GB1012, doi:10.1029/2011GB004039, 2012.

Dutkiewicz, S., Scott, J. R., and Follows, M. J.: Winners and losers: phytoplankton habitat and productivity shifts in a warmer ocean, Global Biogeochem. Cy., 26, GB1012, doi:10.1029/2011GB004039, doi:10.1002/gbc.20042, 2013.

Elrod, V. A., Berelson, W. M., Coale, K. H., and Johnson, K. S.: The flux of iron from continental shelf sediments: a missing source for global budgets, Geophys. Res. Lett., 31, L12307, doi:10.1029/2004GL020216, 2004.

Eppley, R. W.: Temperature and phytoplankton growth in the sea, Fish. B.-NOAA, 70, 1063-1085, 1972.

Finkel, Z. V., Beardall, J., Flynn, K. J., Quigg, A., Rees, T. A. V., and Raven, J. A.: Phytoplankton in a changing world: cell size and elemental stoichiometry, J. Plankton Res., 32, 119-137, doi:10.1093/plankt/fbp098, 2010.
Foster, R. A., Kuypers, M. M. M., Vagner, T., Paerl, R. W., Musat, N., and Zehr, J. P.: Nitrogen fixation and transfer in open ocean diatom-cyanobacterial symbioses, ISME J., 5, 1484-1493, 2011.

Garcia, H. E., Locarnini, R. A., Boyer, T. P., and Antonov, J. I.: World Ocean Atlas 2005, vol. 4, Nutrients (Phosphate, Nitrate, Silicate), in: NOAA Atlas NESDIS, vol. 64, edited by: Levitus, S., 396 pp., NOAA, Silver Spring, Md., 2006.

Geider, R. J., MacIntyre, H. L., and Kana, T. M.: A dynamic regulatory model of photoacclimation to light, nutrient and temperature, Limnol. Oceanogr., 43, 679-694, 1998.

Gent, P. R. and McWilliams, J. C.: Isopycnal mixing in ocean circulation models, J. Phys. Oceanogr., 20, 150-155, 1990.

Gruber, N. and Sarmiento, J. L.: Global patterns of marine nitrogen fixation and denitrification, Global Biogeochem. Cy., 11, 235266, 1997.

Halm, H., Lam, P., Ferdelman, T. G., Lavik, G., Dittmar, T., LaRoche, J., D'Hondt, S., and Kuypers, M. M. M.: Heterotrophic organisms dominate nitrogen fixation in the South Pacific Gyre, The ISME J., 6, 1238-1249, doi:10.1038/ismej.2011.182, 2012.

Hickman, A. E., Dutkiewicz, S., Williams, R. G., and Follows, M. J.: Modelling the effect of chromatic adaptation on phytoplankton community structure in the oligotrophic ocean. Mar. Ecol. Prog. Ser., 406, 1-17, 2010.

Hutchins, D. A., Fu, F., Webb, E., Walworth, N., and Tagliabue, A.: Taxon-specific response of marine nitrogen fixers to elevated carbon dioxide concentrations, Nat. Geosci., 6, 790-795, doi:10.1038/ngeo1858, 2013.

Knapp, A. N., Sigman, D. M., and Lipschultz, F.: N isotopic composition of dissolved organic nitrogen and nitrate at the Bermuda Atlantic Timeseries Study site, Global Biogeochem. Cy., 19, GB1018, doi:10.1029/2004GB002320, 2005.

Knapp, A. N., DiFiore, P. J., Deutsch, C., Sigman, D. M., and Lipschultz, F.: Nitrate isotopic composition between Bermuda and Puerto Rico: implications for $\mathrm{N}_{2}$ fixation in the Atlantic Ocean, Global Biogeochem. Cy., 22, GB3014, doi:10.1029/2007GB003107, 2008.

Krishnamurty, A. J., Moore, K., Mahowald, N., Luo, C., Doney, S., Lindsay, K., and Zender, C.: The impacts of increasing anthropogenic soluble iron and nitrogen deposition on ocean biogeochemistry, 2009, Global Biogeochem. Cy., 23, GB3016, doi:10.1029/2008GB003440, 2009.

Kustka, A. S., Sañudo-Wilhelmy, S., Carpenter, E. J., Capone, D. G., and Raven, J. A.: A revised estimate of the iron efficiency of nitrogen fixation with special reference to the marine cyanobacterium Trichodesmium spp. (cyanophyta), J. Phycol., 39, 12-25, 2003.

Large, W. G., McWilliams, J. C., and Doney, S. C.: Oceanic vertical mixing: a review and a model with a nonlocal boundary layer parameterization, Rev. Geophys., 32, 363-403, 1994.

Le Quéré, C. L., Harrison, S. P., Colin Prentice, I., Buitenhuis, E. T., Aumont, O., Bopp, L., Claustre, H., Cotrim Da Cunha, L., Geider, R., Giraud, X., Klaas, C., Kohfeld, K. E., Legendre, L., Manizza, M., Platt, T., Rivkin, R. B., Sathyendranath, S., Uitz, J., Watson, A. J., and Wolf-Gladrow, D.: Ecosystem dynamics based on plankton functional types for global ocean biogeochemistry models, Glob. Change Biol., 11, 2016-2040, doi:10.1111/j.13652486.2005.1004.x, 2005.

Levitan, O., Rosenberg, G., Setlik, I., Setlikova, E., Grigel, J., Klepetar, J., O. Prasil, and Berman-Frank, I.: Elevated $\mathrm{CO}_{2}$ en- 
hances nitrogen fixation and growth in the marine cyanobacterium Trichodesmium, Glob. Change Biol., 13, 531-538, doi:10.1111/j.1365-2486.2006.01314.x, 2007.

Luo, C., Mahowald, N., Bond, T., Chuang, P. Y., Artaxo, P., Siefert, R. , Chen, Y., and Schauer, J.: Combustion iron distribution and deposition, Global Biogeochem. Cy., 22, GB1012, doi:10.1029/2007GB002964, 2008.

Luo, Y.-W., Doney, S. C., Anderson, L. A., Benavides, M., BermanFrank, I., Bode, A., Bonnet, S., Boström, K. H., Böttjer, D., Capone, D. G., Carpenter, E. J., Chen, Y. L., Church, M. J., Dore, J. E., Falcón, L. I., Fernández, A., Foster, R. A., Furuya, K., Gómez, F., Gundersen, K., Hynes, A. M., Karl, D. M., Kitajima, S., Langlois, R. J., LaRoche, J., Letelier, R. M., Marañón, E., McGillicuddy Jr., D. J., Moisander, P. H., Moore, C. M., Mouriño-Carballido, B., Mulholland, M. R., Needoba, J. A., Orcutt, K. M., Poulton, A. J., Rahav, E., Raimbault, P., Rees, A. P., Riemann, L., Shiozaki, T., Subramaniam, A., Tyrrell, T., Turk-Kubo, K. A., Varela, M., Villareal, T. A., Webb, E. A., White, A. E., Wu, J., and Zehr, J. P.: Database of diazotrophs in global ocean: abundance, biomass and nitrogen fixation rates, Earth Syst. Sci. Data, 4, 47-73, doi:10.5194/essd-4-47-2012, 2012.

Luo, Y.-W., Lima, I. D., Karl, D. M., Deutsch, C. A., and Doney, S. C.: Data-based assessment of environmental controls on global marine nitrogen fixation, Biogeosciences, 11, 691-708, doi:10.5194/bg-11-691-2104, 2014.

Mahowald, N. and Luo, C.: A less dusty future?, Geophys. Res. Lett., 30, 1903, doi:10.1029/2003GL017880, 2003.

Mahowald, N. M., Muhs, D. R., Levis, S., Rasch, P. J., Yoshioka, M., Zender, C. S., and Luo, C.: Change in atmospheric mineral aerosols in response to climate: last glacial period, pre industrial, modern, and doubled carbon dioxide climates, J. Geophys. Res., 111, D10202, doi:10.1029/2005JD006653, 2006.

Marshall, J., Adcroft, A., Hill, C. N., Perelman, L., and Heisey, C.: A finite-volume, incompressible Navier-Stokes model for studies of the ocean on parallel computers, J. Geophys. Res., 102, 5753-5766, 1997.

Mills, M. M. and Arrigo, K. R.: Magnitude of oceanic nitrogen fixation influenced by the nutrient uptake ratio of phytoplankton, Nat. Geosci., 3, 412-416, 2010.

Monteiro, F. M., Follows, M. J., and Dutkiewicz, S.: Distribution of diverse nitrogen fixers in the global ocean, Global Biogeochem. Cy., 24, GB3017, doi:10.1029/2009GB003731, 2010.

Moore, C. M., Mills, M. M, Achterberg, E. P., Geider, R. J., LaRoche, J., Lucas, M. I., McDonaag, E. L., Pan, X., Poulton, A. J., Rijkenberg, M. J. .A., Suggest, D. J., Ussher, S. J., and Woodward, E. M. S.: Large-scale distribution of Atlantic nitrogen fixation controlled by iron availability, Nat. Geosci., 2, 867871, doi:10.1038/ngeo667, 2009.

Moore, R. M., Kienast, M., Fraser, M., Cullen, J., Deutsch, C., Dutkiewicz, S., Follows, M. J., and Somes, C. J.: Substantial underestimation of nitrogen fixation suggested by hydrogen supersaturations in the Atlantic, J. Geophys. Res.-Oceans, 119, 43404350, 2014.

Parekh, P., Follows, M. J., and Boyle, E. A.: Decoupling of iron and phosphate in the global ocean, Global Biogeochem. Cy., 19, GB2020, doi:10.1029/2004GB002280, 2005.

Riebesell, U., Schulz, K. G., Bellerby, R. G. J., Botros, M., Fritsche, P., Meyerhofer, M., Neill, C., Nondal, G., Os- chlies, A., Wohlers, J. and Zollner, E.: Enhanced biological carbon consumption in a high $\mathrm{CO}_{2}$ ocean, Nature, 450, 545-549, doi:10.1038/nature06267, 2007.

Sarmiento, J. L., Gruber, N., Brzezinski, M, and Dunne, J. P: Highlatitude controls of thermocline nutrients and low latitude biological productivity, Nature, 427, 56-60, 2004.

Schlosser, C., Klar, J. K., Wake, B. D., Snow, J. T., Honey, D. J., Woodward, E. M. S., Lohan, M. C., Achterberg, E. P., and Moore, C. M.: Seasonal ITCZ migration dynamically controls the location of the (sub)tropical Atlantic biogeochemical divide, P. Natl. Acad. Sci. USA, 111, 1438-1442, 2013.

Scott, J. R., Sokolov, A. P., Stone, P. H., and Webster, M. D.: Relative roles of climate sensitivity and forcing in defining the ocean circulation response to climate change, Clim. Dynam., 30, 441454, 2008.

Shi, D., Xu, Y., Hopkinson, B., and Morel, F. M. M.: Effect of ocean acidification on iron availability to marine phytoplankton, Science, 327, 676-679, doi:10.1126.science.1183517, 2010.

Sokolov, A. P., Stone, P. H., Forest, C. E., Prinn, R., Sarofim, M. C., Webster, M., Paltsev, S., Schlosser, C. A., Kicklighter, D., Dutkiewicz, S., Reilly, J., Wang, C., Felzer, B., Jacoby, H. D.: Probabilistic forecast for 21 st century climate based on uncertainties in emissions (without policy) and climate parameters, J. Climate, 22, 5175-5204, doi:10.1175/2009JCLI2863.1, 2009.

Staal, M., Rabouille, S., and Stal, L. J.: On the role of oxygen for nitrogen fixation in the marine cyanobacterium Trichodesmium sp., Environ. Microbiol., 9, 727-736, 2007.

Steinacher, M., Joos, F., Frölicher, T. L., Bopp, L., Cadule, P., Cocco, V., Doney, S. C., Gehlen, M., Lindsay, K., Moore, J. K., Schneider, B., and Segschneider, J.: Projected 21st century decrease in marine productivity: a multi-model analysis, Biogeosciences, 7, 979-1005, doi:10.5194/bg-7-979-2010, 2010.

Tagliabue, A., Bopp, L., and Aumont, O.: Ocean biogeochemistry exhibits contrasting responses to a large scale reduction in dust deposition, Biogeosciences, 5, 11-24, doi:10.5194/bg-5-112008, 2008.

Tagliabue, A., Bopp, L., and Gehlen, M.: The response of marine carbon and nutrient cycles to ocean acidification: large uncertainties related to phytoplankton physiological assumptions Global Biogeochem. Cy., 25, GB3017, doi:10.1029/2010GB003929, 2011.

Tagliabue, A., Mtshali, T., Aumont, O., Bowie, A. R., Klunder, M. B., Roychoudhury, A. N., and Swart, S.: A global compilation of dissolved iron measurements: focus on distributions and processes in the Southern Ocean, Biogeosciences, 9, 2333-2349, doi:10.5194/bg-9-2333-2012, 2012.

Tegen, I., Werner, M., Harrison, S. P., and Kohfeld, K. E.: Relative importance of climate and land use in determining present and future global soil dust emission, Geophys. Res. Lett., 31, L05105, doi:10.1029/2003GL019216, 2004.

Tilman, D.: Resource Competition and Community Structure, Monogr. in Pop. Biol., 17, Princeton Univ. Press, Princeton, NJ, 296 pp., 1982.

Ward, B. A., Dutkiewicz, S., Moore, C. M., and Follows, M. J.: Nutrient supply ratios define ocean biomes, Limnol. Ocean., 58, 2059-2075, 2013.

Weber, T. and Deutsch, C.: Oceanic nitrogen reservoir regulated by plankton diversity and ocean circulation, Nature, 489, 419-422, 2012. 